\title{
Modelling the Caspian Sea and its catchment area using a coupled regional atmosphere-ocean model (RegCM4-ROMS): model design and preliminary results
}

\author{
U. U. Turuncoglu, G. Giuliani, N. Elguindi, and F. Giorgi \\ Earth System Physics Section, International Centre for Theoretical Physics, 34151 Trieste, Italy \\ Correspondence to: U. U. Turuncoglu (uturunco@ictp.it)
}

Received: 10 November 2012 - Published in Geosci. Model Dev. Discuss.: 26 November 2012

Revised: 2 February 2013 - Accepted: 4 February 2013 - Published: 1 March 2013

\begin{abstract}
We describe the development of a coupled regional atmosphere-ocean model (RegCM4-ROMS) and its implementation over the Caspian Sea basin. The coupled model is run for the period 1999-2008 (after a spin up of $4 \mathrm{yr}$ ) and it is compared to corresponding stand alone model simulations and a simulation in which a distributed 1d lake model is run for the Caspian Sea. All model versions show a good performance in reproducing the climatology of the Caspian Sea basin, with relatively minor differences across them. The coupled ROMS produces realistic, although somewhat overestimated, Caspian Sea Surface Temperature (SST), with a considerable improvement compared to the use of the simpler coupled lake model. Simulated near surface salinity and sea currents are also realistic, although the upwelling over the eastern coastal regions is underestimated. The sea ice extent over the shallow northern shelf of the Caspian Sea and its seasonal evolution are well reproduced, however, a significant negative bias in sea-ice fraction exists due to the relatively poor representation of the bathymetry. ROMS also calculates the Caspian Sea Level (CSL), showing that for the present experiment excessive evaporation over the lake area leads to a drift in estimated CSL. Despite this problem, which requires further analysis due to many uncertainties in the estimation of CSL, overall the coupled RegCM4-ROMS system shows encouraging results in reproducing both the climatology of the region and the basic characteristics of the Caspian Sea.
\end{abstract}

\section{Introduction}

Situated in southwestern Asia and covering approximately $400000 \mathrm{~km}^{2}$, the Caspian Sea is the largest enclosed sea in the world. The main sources of water inflow come from the Volga, Ural and Kura rivers, which contribute to over $90 \%$ of the total runoff to the Sea. The Caspian Sea level (CSL) is constrained only by river discharge, and precipitation and evaporation over the Sea and, thus, is very sensitive to changes in the climate system over the region. Historically, the CSL has fluctuated dramatically, decreasing by over two metres between 1933 and 1940, and then increasing again by about two metres in the late 1970s and early 1980s. These fluctuations in the CSL have been attributed to climate-driven changes in the basin's hydrologic regime (Rodionov, 1994). The rapid changes in the CSL of the past have had dramatic impacts in the region, particularly in the northern coastal areas, which are vulnerable to flooding. Previous studies have shown that it is probable that projected changes in global and regional climates will produce large changes in the Caspian Sea's characteristics (Elguindi and Giorgi, 2006a,b, 2007), which could result in massive impacts on the environmental and socioeconomic conditions of the region. Thus, understanding the hydrodynamic properties (i.e., main circulation and thermal structure) of the Caspian Sea and its complex interaction with the regional climate has become of paramount interest in recent decades (Elguindi and Giorgi, 2006a,b, 2007; Elguindi et al., 2011; Anisimov et al., 2011).

Past studies have demonstrated the influence of large lakes on regional climate for the Great Lakes (Bates et al., 1993, 1995; Notaro et al., 2013) and Lake Victoria 
(Anyah et al., 2006). Using a regional climate model (RCM), Bates et al. (1995) estimated that the presence of the lakes could account for as much as $25 \%$ of the precipitation over the basin. Scott and Huff (1996) found that winter precipitation could increase by as much as $100 \%$ and surface air temperature by $10-15 \%$ due to the lakes. Substantial changes in cloud cover were also noted by Scott and Huff (1996) and Notaro et al. (2013). Modelling studies have also shown that the presence of Lake Victoria has a large influence on the surrounding climate (Anyah and Semazzi, 2004; Anyah et al., 2006).

Despite it's importance, few, if any, studies have investigated the complex interactions and feedback mechanisms between the Caspian Sea and the surrounding climate. Most past studies have focused on understanding either the dynamics of the Sea (i.e., seasonal variability in circulation, temperature and salinity distribution) using stand-alone 3-D ocean models (Ibrayev et al., 2001; Kara et al., 2010) or the regional climate and it's impact on the basin's hydrologic balance using climate models (Golitsyn et al., 1995; Arpe et al., 2000; Arpe and Leroy, 2007; Elguindi and Giorgi, 2006a,b, 2007; Elguindi et al., 2011). While these studies have contributed a great deal to understanding the impact of regional climate on the basin's hydrological balance or on the dynamics of the Sea, there is clearly a need to link the two and explore the complex interactions and feedback mechanisms between the Sea and the climate of the surrounding region. A study of this nature necessitates the use of a fully coupled regional atmosphere-ocean model. The purpose of this paper is to introduce the design of such a model (RegCM4-ROMS) and to present preliminary results of simulations performed over the Caspian Sea basin. In order to highlight improvements gained by the use of the fully coupled model, comparisons are made with simulations using the RCM either in stand-alone mode, or coupled to a one-dimensional lake model (Turuncoglu et al., 2012). The seasonal variability of the main circulation, thermal structure and ice distribution of the Caspian Sea is also examined by using results from the different model configurations.

The rest of this paper is organised as follows: the description of the individual modelling components and the design of the coupled modelling system are given in Sect. 2. Section 3 presents the experiment design, observational data and analysis methodology, while Sect. 4 discusses the results from our experiments. The last section then presents conclusions and outlook for future work.

\section{Model description}

This section aims to present the newly designed coupled modelling system beginning with short descriptions of each model component followed by an overview of the general design.

\subsection{Regional Climate Model (RegCM4)}

The dynamical core of the RegCM is based on the primitive equation, hydrostatic version of the National Centre for Atmospheric Research (NCAR) and Pennsylvania State University mesoscale model MM5 (Grell et al., 1995). The model includes the Biosphere-Atmosphere Transfer Scheme (BATS; Dickinson et al., 1989) along with the ocean/atmosphere flux parameterisation of Zeng et al. (1998). The model also contains the nonlocal boundary layer scheme of Holtslag et al. (1990) (as argumented by Giorgi et al., 2012), the radiative transfer package of NCAR Community Climate Model Version 3 (CCM3; Kiehl et al., 1996), the explicit cloud/precipitation scheme of Pal et al. (2000), and the Grell cumulus convective scheme (Grell, 1993). More details about RegCM4 can be found in Giorgi et al. (2012).

The current version is also coupled to the one-dimensional diffusion-convection lake model described by Hostetler et al. (1993). In the lake model, energy is transferred between layers by eddy and molecular diffusion and by vertical convective mixing. The lake model is run at each model grid point with no exchange across the grid points. The Hostetler lake model is coupled to a one-layer ice model, which is based on the work by Patterson and Hamblin (1988). The ice model simulates the accretion and ablation of ice and the ablation of snow covering the ice layer. Freezing occurs when the surface temperature of the lake reaches a certain threshold value. The grid cell is considered to be completely ice covered once the ice reaches a thickness of $10 \mathrm{~cm}$. The coupled RegCMHostetler lake model has already been used for lakes in the US (Hostetler et al., 1993), the Aral Sea (Small et al., 1999), and the Caspian Sea (Turuncoglu et al., 2012).

Some parameters of the one-dimensional lake model (vertical heat diffusion coefficient and the absorption of solar radiation in the water) were customised to optimise the overall fit to observed mean Caspian sea surface temperature (SST) after a series of preliminary experiments (see Turuncoglu et al., 2012).

\subsection{Regional Ocean Modelling System (ROMS)}

ROMS is a three-dimensional, free-surface, terrain-following numerical ocean model that solves the Reynolds-averaged Navier-Stokes equations using the hydrostatic and Boussinesq assumptions. The governing equations are in flux form and the model uses Cartesian horizontal coordinates and sigma vertical coordinates with three different stretching functions (Shchepetkin and McWilliams, 2005; Haidvogel et al., 2008). The model also supports second, third and fourth order horizontal and vertical advection schemes for momentum and tracers via its preprocessor flags.

The ROMS model has wetting and drying capabilities, which may be of great importance when performing longterm climate simulations. The grid cell can switch between being wet or being dry (by changing its land-sea mask 
values) as the sea level increases and decreases. In our experiment, however, the cells, which are defined as land points at the beginning of the simulation, are never allowed to be wet. Based on the wetting and drying algorithm, the ocean model grid cells which have depths less than a user-specified value $D_{\text {crit }}$ are defined as dried grid cells, and the model prevents any outward flux of water from those cells. This process is called cell flux blocking (Casulli and Cheng, 1992). In this version, water can move into dried grid cells to convert them into ocean grid points.

The version of ROMS used here is also coupled to an ice model (Budgell, 2005). Sea ice is represented using a combination of elastic-viscous-plastic rheology (Hunke and Dukowicz, 1997; Hunke, 2001) and a simple one-layer ice and snow thermodynamic model with a molecular sublayer under the ice (Mellor and Kantha, 1998). This version of the model is based on the Rutgers University ROMS version 3.5 (Shchepetkin and McWilliams, 2005).

\subsection{Implementation of the coupled atmosphere-ocean model}

In a previous study, Ratnam et al. (2009) coupled earlier versions of RegCM3 and ROMS using an ad-hoc climate procedure. Here we follow a different approach. The easiest way to design a coupled modelling system is to use a special programming interface or coupler library, which is designed to merge different model components in an efficient and optimised manner. The Earth System Modelling Framework (ESMF; Hill et al., 2004a,b; Collins et al., 2005), Model Coupling Toolkit (MCT; Jacob et al., 2005; Larson et al., 2005), Model Coupling Environmental Library (MCEL; Bettencourt, 2002) and Ocean Atmosphere Sea Ice Soil (OASIS; Redler et al., 2010) coupler can be given as examples of this approach, by which the complexity of the regular tasks to create a coupled modelling system (synchronisation of the model components, exchanging coupling fields among modelling components, interpolation between different grids, etc.) can be simplified. In this study, the Earth System Modelling Framework (ESMF, version 5.2.0rp3) library was selected to couple the RegCM4 and ROMS in view of it's unique online re-gridding capability which allows the coupler to readily perform different interpolation types (bilinear, conservative, etc.) over the exchange fields (i.e., sea surface temperature, heat and momentum fluxes). In this way, the ESMF library creates a more efficient and easy to use single executable version of the coupled model with online re-gridding capability, which does not exist in Ratnam et al. (2009). In addition, the current version of the coupled model also supports to use of ROMS with the ice model, which has crucial importance to study the northern Caspian Sea in the winter season.

The ESMF consists of a superstructure for coupling model components in a standardised way and an infrastructure of robust, high-performance utilities and data structures that

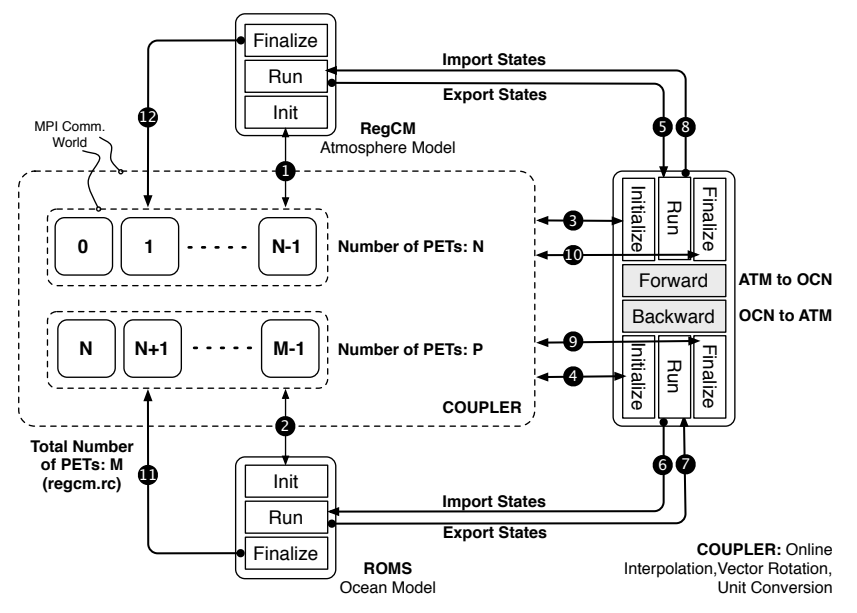

Fig. 1. General structure of coupled modelling system. The dashed rectangles indicate the MPI communication world specific to components (RegCM4, ROMS and Coupler). The solid rectangles represent the component codes and the black solid circles show the execution order of the components.

ensure consistent component behaviour (Hill et al., 2004a,b; Collins et al., 2005). The overall structure of the designed coupled modelling system is presented in Fig. 1. There are three different ESMF components: two gridded (RegCM4 and ROMS models) and one coupler (Coupler) component. The gridded components are described as a user code or the physical model, which are written either in $\mathrm{C} / \mathrm{C}++$ or Fortran programming language. In addition to the user code, the coupler component is responsible for preparing and exchanging information between gridded components via ESMF state variables. Each of the gridded components runs concurrently in their communication world (a group of Persistent Execution Threads - PETs). In ESMF terminology, the single processing unit (i.e., CPU, core or a thread) is defined as Persistent Execution Threads or PETs. In the current version of the coupled modelling system, PETs are divided among the gridded components in a user configurable way and the coupler component uses all the available PETs to perform interpolation. The coupler component also runs in both directions: forward (from RegCM4 to ROMS) and backward (from ROMS to $\mathrm{RegCM} 4)$.

At the beginning of the execution of the coupled model, all the ESMF components (gridded and coupler) are created and initialised (Fig. 1, step 1-4). In this case, the processes are executed in parallel because there is no any dependency among the components in the model initialisation phase. Please note that the step 1 and 2 only works on the specific subset of the PETs, but step 3 and 4 distributed via all the available PETs because the coupler component will perform interpolation using all the PETs. Then, the gridded components are run in order (Fig. 1, step 5-8) until the simulation ends and data are exchanged between gridded components in a defined interval (coupling time step). Unlike initialisation phase, the 
execution order will be sequential in this case due to the data dependency among model components (in both direction, forward and backward), but each component (models and the coupler) will run in parallel inside of their own MPI communication world (a subset of PETs). In each loop, the coupler component interpolates the data between component grids, rotates the wind components and applies unit conversions. At the end of the simulation, the main programme calls the final routines of each gridded and coupler component (Fig. 1, step 9-11). The finalisation phase (step 9-12) will also be sequential because ESMF needs to destroy the components in a specific order (first coupler component and then model components).

In the forward mode, the atmosphere model sends surface atmospheric conditions to the ocean model (see Figs. 1-2). In this case, two different options are supported: (1) sending surface atmospheric variables (i.e., surface temperature, pressure, mixing ratio, wind components, rain and longwave and shortwave fluxes) to the ocean model to calculate net heat and momentum fluxes over sea and ice by using bulk aerodynamic module, (2) sending net heat, freshwater and momentum fluxes. The second option can be considered superior because it allows better conservation of the fluxes between model components. In the backward mode, the ocean model interacts with the atmosphere via its coupler interface to update ground temperature (sea surface temperature over ocean or inland waters) and ice thickness. During the execution, time exchange fields (in both direction) are updated at each coupling time interval.

In the current implementation, the coupled modelling system also supports conservative type interpolation to exchange area dependent flux variables. This allows the coupler to prevent artificial energy flux from entering the ocean model. The coupled model is designed to use both the Zeng ocean/atmosphere flux parameterisation and the onedimensional lake model along with ROMS. This allows different types of ocean/atmosphere parameterisations (BATS or CLM, Zeng or ROMS) to be used over different areas of the atmospheric model domain, producing a more flexible modelling system (Fig. 2).

\section{Experiment design and observational datasets}

In this study, we assess and intercompare the following set of simulations: (1) RCM simulation (ATM.STD) using prescribed SST (OISST; Reynolds et al., 2002) data for the Caspian Sea, (2) RCM simulation with one-dimensional lake model activated for Caspian Sea (ATM.LAK), (3) RCM simulation coupled with ROMS configured for Caspian Sea (ATM.CPL and OCN.CPL), and (4) stand-alone ROMS forced by data from ATM.STD (OCN.STD). The ATM.CPL and OCN.CPL results are produced in the same simulation, but represent the separate components (atmosphere $50 \mathrm{~km}$ horizontal resolution and ocean $10 \mathrm{~km}$ horizontal resolution) of the coupled modelling system.

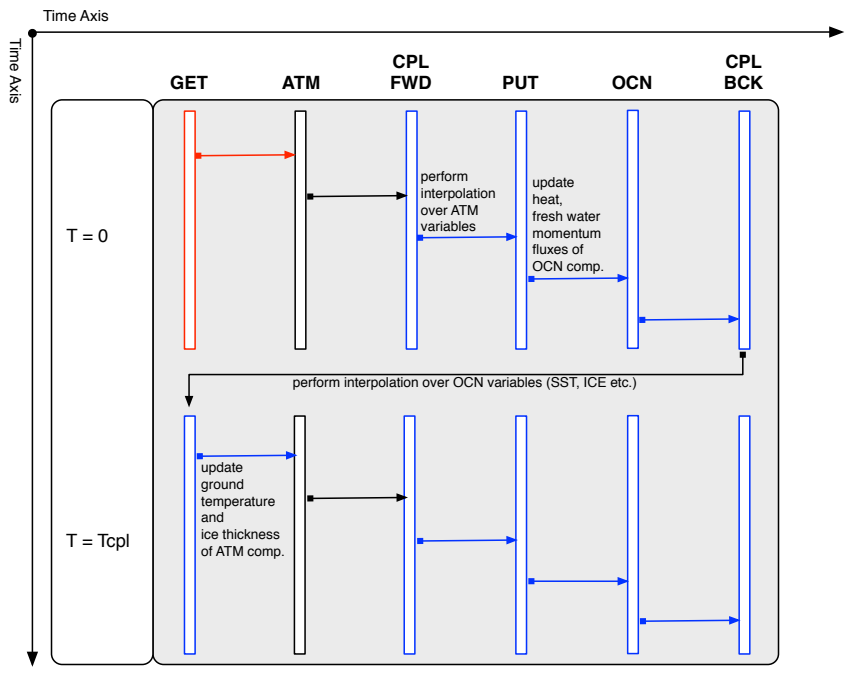

Fig. 2. Execution order of the model code. The black solid rectangles represent the component codes that always run. The blue and red rectangles indicate the sub-routines that can execute only when the model coupling is activated. The red rectangle indicates the skipped code part.

The model domain, topography and ocean model bathymetry are shown in Fig. 3. The configuration details regarding atmosphere and ocean models are presented in the following subsections. The configurations of the individual model components are kept the same in all simulations and the coupled time step, which controls the data exchange interval between the modelling components, is set to $3 \mathrm{~h}$ (ATM.CPL and OCN.CPL).

\subsection{Atmosphere model}

Figure 3a shows the RegCM4 domain, topography, location of the ROMS grid and the major river basins (Volga, Kura and Ural). The atmospheric model has a $50 \mathrm{~km}$ horizontal resolution and 18 vertical sigma layers. The one-dimensional lake model (only activated in ATM.LAK) has the same horizontal resolution as the atmospheric model $(50 \mathrm{~km})$ and a vertical resolution of one metre (maximum depth is set to $300 \mathrm{~m}$ ). For the ATM.STD, ATM.LAK and ATM.CPL simulations, the initial and lateral boundary conditions are derived from the European Centre for Medium-Range Weather Forecasts (ECMWF) latest global atmospheric reanalysis (ERAInterim project; Dee et al., 2011), which is available at 6-h intervals at a resolution of $1.5^{\circ} \times 1.5^{\circ}$ in the horizontal and 37 pressure levels in the vertical. The sea surface temperature (SST) and sea-ice data for the corresponding regional climate simulations were prescribed from the National Oceanic and Atmospheric Administration (NOAA) Optimum Interpolation SST (OISST) dataset with a weekly temporal resolution and $1^{\circ} \times 1^{\circ}$ spatial resolution (Reynolds et al., 2002). The surface fluxes, which are passed to both the ocean and onedimensional lake models, are calculated by the land surface 


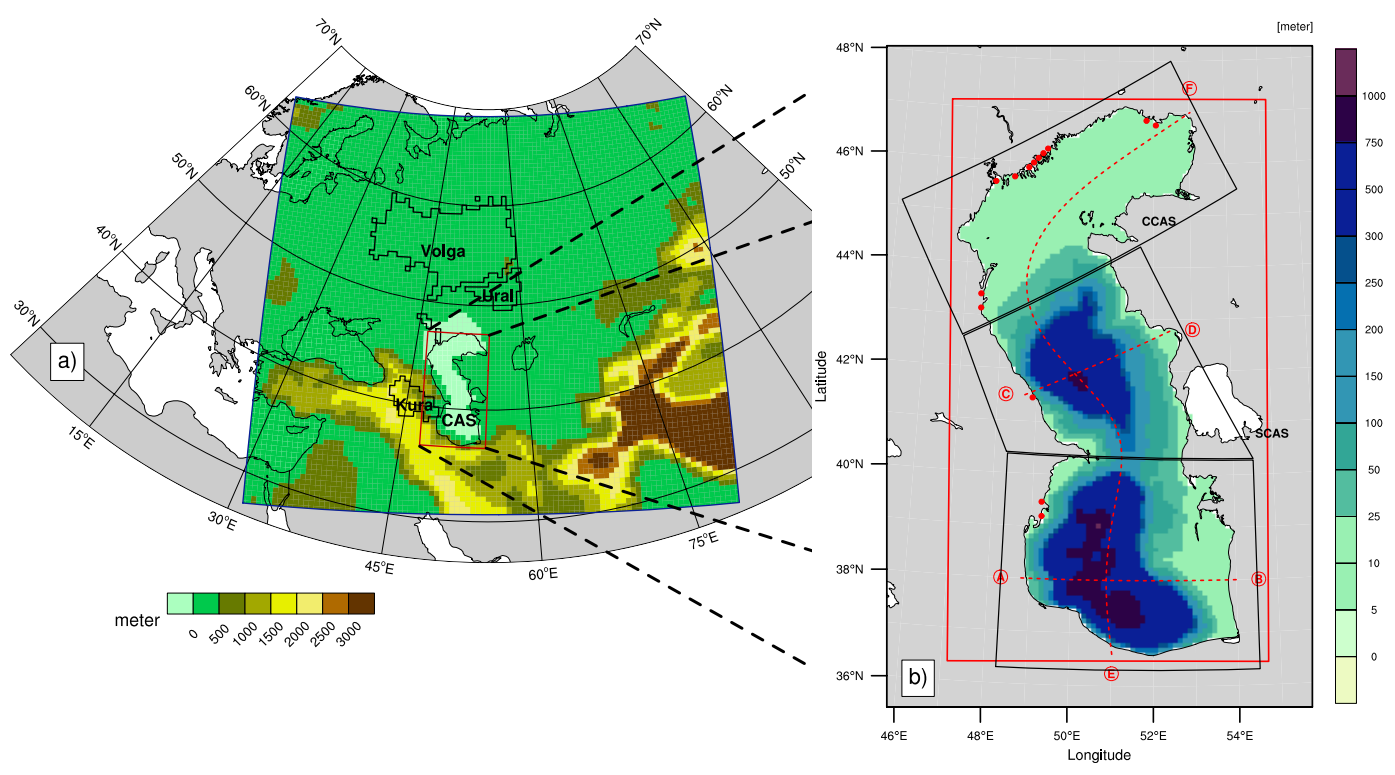

Fig. 3. RCM domain, topography and ocean model bathymetry. (a) Caspian Sea (CAS) region domain and topography used in the RCM simulations. The outer blue solid box is the $50 \mathrm{~km}$ RCM domain and inner red solid box is the ROMS ocean model domain. The regions indicated by solid black lines, which are the main basins (Volga, Ural and Kura), extracted from TRIP dataset. (b) Ocean model bathymetry, defined river locations, sub regions and cross-sections.

model BATS. The simulations span the period from 1995 to 2008 with the first four years considered as "spin-up" and discarded from the analysis which, therefore, uses the remaining 10-yr (1999-2008).

\subsection{Ocean model}

In the ocean model, the horizontal grid spacing is defined as approximately $10 \mathrm{~km}$ (the Rossby radius of deformation in the Caspian Sea is around $15 \mathrm{~km}$ ), with 32 vertical sigma levels $\left(\theta_{\mathrm{s}}=7.0\right.$ and $\left.\theta_{\mathrm{b}}=0.2\right)$, resulting in $67 \times 119$ grid points (see Fig. 3b). The bottom topography data of the Caspian Sea is constructed using the ETOPO1 dataset (Amante and Eakins, 2009) by modifying mean sea level to $-27.75 \mathrm{~m}$ and minimum depth $\left(H_{\mathrm{b}}\right)$ to $5 \mathrm{~m}$. Fixing the minimum depth has a critical impact on ice formation in the northern part of the Caspian Sea. The bathymetry data are modified so that the ratio of depths of any two adjacent grids does not exceed 0.25. This ensures the hydrostatic consistency creation for sigma coordinates following the method of Sikiric et al. (2009).

The generic length scale (GLS) scheme of Warner et al. (2005) is used to represent sub-grid scale mixing of mass and momentum, with the two-equation $k-\theta$ model parameters. The time step used in the simulation is $300 \mathrm{~s}$ for both the ocean internal mode and the ice thermodynamics. The ratio of ocean internal to external mode time step is defined as 20 . A Harmonic lateral mixing coefficient is used with constant viscosity and diffusivity of $10 \mathrm{~m}^{2} \mathrm{~s}^{-1}$ and $50 \mathrm{~m}^{2} \mathrm{~s}^{-1}$. The background mixing coefficients for momentum and tracer are set to $1 \times 10^{-5}$ and $1 \times 10^{-6} \mathrm{~m}^{2} \mathrm{~s}^{-1}$, respectively. In this application, we also activated the ROMS wetting and drying scheme for modelling the shallow region (northern part of the Caspian Sea, NCAS) depth. As mentioned, the algorithm identifies cells with water depths less than a user-specified value ( $D_{\text {crit }}$ ), here set as $0.2 \mathrm{~m}$ to avoid instabilities and prevents outward flux of water from those cells.

The majority of water inflow to the Caspian Sea is provided by the Volga ( $80 \%$ of the mean river discharge), Ural $(3 \%)$ and Kura (6\%) rivers (see Fig. 3b). The river discharge plays an important role in the conservation of water mass and in the dynamics of the Sea (especially in the northern part) by providing freshwater input, which affects the salinity. In this study, ROMS is configured to include six major rivers (Volga, Kura, Ural, Terek, Sulak and Samur) as a point source of freshwater to a few surface layers (see red dots in Fig. 3b). The global river discharge data, which is provided by the Global Runoff Data Centre (GRDC) Koblenz, Germany, and data provided by personal communication (Georgievsky et al., 2003) are used to create monthly river input for ROMS. To represent the Volga River and its connection to the Caspian Sea more realistically, the point source is divided into seven distinct discharge points with equal discharge weights. Similarly, the Ural and Kura have two river discharge points. The rest of the rivers are defined as a single river discharge point for each river. This method allows us to overcome possible instability issues arising from inserting all of the fresh water into the Sea at single river points. We do not use runoff produced by the RegCM4 due to the excessively crude representation of related processes in BATS. 
The ocean model simulations (OCN.CPL and OCN.STD) are initialised with results of a $15-y r$ spin-up simulation. After the 15-yr spin-up, the model reaches steady state in which a three-dimensional relaxation of temperature and salinity is applied to the monthly climatological values provided by Ibrayev et al. (2001). Please note that the three-dimensional temperature and salinity relaxation is activated only in the spin-up run not in the OCN.STD and OCN.CPL simulations. The ATM.STD simulation results are used to create forcing data (heat and momentum fluxes etc.) for both the spin-up run and stand-alone ocean model case (OCN.STD).

\subsection{Observational datasets}

The results presented here focus on the hydrodynamic properties (temperature, salinity, surface currents and lake ice distribution) of the Caspian Sea, as well as the mean climatology of the Volga, Kura and Ural basins. An analysis of the water (precipitation, evaporation and river discharge) and heat flux (latent heat, sensible heat, longwave and incoming solar radiation) budgets, which are also important in terms of ocean-atmosphere interactions, is also presented.

For validating the atmospheric component of the model, we focus on surface temperature and precipitation over the three major river basins (Volga, Kura, Ural) defined from a grid extracted from the Total Runoff Integrating Pathways (TRIP) dataset Oki and Sud (1998). Simulated temperature and precipitation results are validated against two different ground station-based observational datasets: the global ground-station based half-degree datasets produced by the Climate Research Unit (CRU, version 3.10) of the University of East Anglia for temperature and precipitation (New et al., 2000) and the global monthly temperature and precipitation half degree datasets produced by the University of Delaware (UDEL 3.1; Legates and Willmott, 1990a,b).

Our validation of the ocean model focuses on sea surface temperature (SST), salinity (LSS), their vertical profiles over defined cross sections (see Fig. 3b), surface currents and ice cover. For observations we utilise the recently released ATSR Reprocessing for Climate: Lake Surface Water Temperature and Ice Cover (ARCLAKE) product, which is a global database of SST and ice (LIC). The ARCLAKE project provides data for large natural lakes with surface area greater than $500 \mathrm{~km}^{2}$, with temporal coverage from 1995 to 2009 and spatial resolution of $0.05^{\circ}$. The product is derived from ATSR-2/AATSR satellite observations by applying a specialised SST retrieval scheme for the lakes (MacCallum and Merchant, 2011). For the validation of vertical temperature and salinity profiles, we use monthly climatology values obtained from Ibrayev et al. (2001). The horizontal resolution of the dataset is $0.25^{\circ} \times 0.25^{\circ}$ and the vertical depth levels are at $0,5,10,15,20,25,30,50,75,100,125,150,200,250$, $300,400,500,600$ and $800 \mathrm{~m}$. However, it should be noted that the Ibrayev's climatology is based on the unknown years (we could not get the Ibrayev's original paper that includes detailed information about the climatological data), which is different from our model climatology (1999-2008). While a comparison between the two climatologies is not ideal, it can nonetheless give an idea of the general model performance.

To extend our analysis, we also compare the simulated Caspian Sea Level (CSL) variations with the lake and reservoir surface height variations from the USDA's Global Reservoir and Lake (GRLM) available at: http://www.pecad.fas. usda.gov/cropexplorer/global_reservoir/, 2012 and altimetric lake level time-series variations from the Topex/Poseidon, Jason-1, Jason-2/OSTM, and Geosat Follow-On (GFO) missions data.

\subsection{Results}

\subsubsection{Surface air temperature and precipitation}

We begin our analysis with a brief assessment of the simulated surface climatology in the various experiments. Seasonal surface air temperature averages from the ATM.STD and ATM.CPL simulations, as well as the CRU observations and associated biases, are presented in Fig. 4. In both simulations, the model reproduces the observed temperature spatial patterns reasonably well in all seasons, especially over the Caspian Sea basin where biases for the most part are less than $1-2{ }^{\circ} \mathrm{C}$. An exception is the warm summer bias that exists to the northwest of the Caspian Sea and in the Volga basin. This warm bias exists in all runs and is most likely related to the dry summer bias over the same region, as discussed in the following section. Although not shown, the ATM.LAK simulation also indicates generally similar results for surface temperature in both spatial pattern and magnitude of the biases. The large warm winter biases east and north-east of the Caspian Sea basin are associated with excessive vertical heat transport in the Holtslag scheme under very stable conditions and is also inherited from the driving ERA-Interim reanalysis (see also Turuncoglu et al., 2012).

As a measure of how the model reproduces observed interannual variability, Fig. 5 compares observed and simulated warm season (April-September) monthly averaged temperature anomalies for the period 1999-2008 over the three main river basins. Temperature during the warm season is an important indicator of potential evaporation over the Caspian Sea basin. In all cases, it is clear that the model reproduces the observed anomalies for the simulated period. The correlations between simulations and observational datasets for temperature anomalies are all over 0.82, with ATM.CPL having the highest correlation of $\sim 0.86$.

Figure 6 shows simulated (ATM.STD and ATM.CPL) and observed (CRU) precipitation along with the corresponding relative biases, and Table 1 reports the simulated and observed averaged precipitation values for the areas covered by the Volga, Kura and Ural basins. As seen from the figure, the spatial pattern and magnitude of simulated precipitation consistent with observations. The biases are 


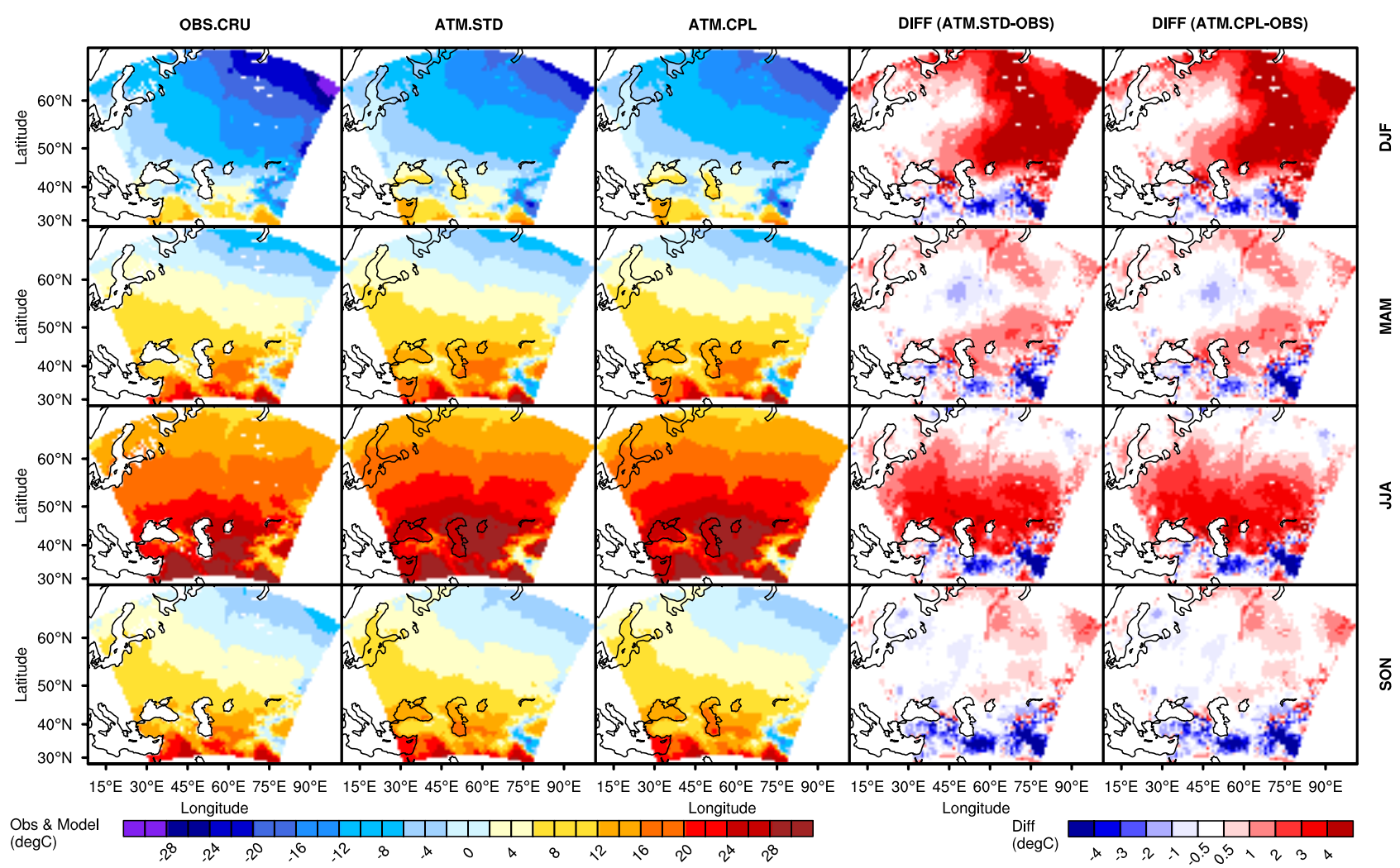

Fig. 4. Seasonal temperature climatology of ATM.STD, ATM.CPL simulations and observation (CRU), along with the corresponding biases for the period 1999-2008.

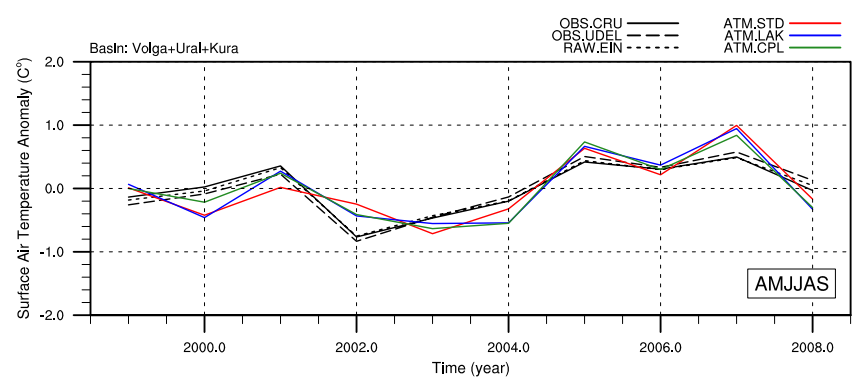

Fig. 5. Anomalies of warm season (from April to September) surface air temperature $\left({ }^{\circ} \mathrm{C}\right)$ for the period $1999-2008$ in the model simulations and the different observation datasets. The domain only includes the Volga, Kura and Ural basins shown in Fig. 3a (extracted from the Total Runoff Integrating Pathways, or TRIP, dataset).

relatively small and similar for all simulations when looking at basin-averaged values (Table 1). The largest bias occurs in the winter and spring where all simulations (ATM.STD, ATM.LAK and ATM.CPL) produce 40-60\% more precipitation over the western Kazakhstan region compared to the observations. It should be noted, however, that the observations used here do not include an under-catch correction, which may be up to $20-30 \%$ in winter conditions (Adam and Lettenmaier, 2003).
Table 1. Seasonal and annual basin averaged (Volga, Kura and Ural) precipitation $\left(\mathrm{mm} \mathrm{day}^{-1}\right)$ for the period 1999-2008 in the three RCM simulations (ATM.STD, ATM.LAK and ATM.CPL) and the different observation datasets. EIN is ERA Interim Re-analysis data, which is used to drive RCM.

\begin{tabular}{lcccccc}
\hline & $\begin{array}{c}\text { ATM } \\
\text { STD }\end{array}$ & $\begin{array}{c}\text { ATM } \\
\text { LAK }\end{array}$ & $\begin{array}{c}\text { ATM } \\
\text { CPL }\end{array}$ & EIN & UDEL & CRU \\
\hline DJF & 1.42 & 1.42 & 1.44 & 1.39 & 1.17 & 1.12 \\
MAM & 1.63 & 1.65 & 1.65 & 1.57 & 1.11 & 1.19 \\
JJA & 1.62 & 1.80 & 1.68 & 2.33 & 1.57 & 1.86 \\
SON & 1.57 & 1.68 & 1.64 & 1.68 & 1.37 & 1.51 \\
ANN & 1.55 & 1.63 & 1.60 & 1.73 & 1.30 & 1.42 \\
\hline
\end{tabular}

Again, as a measure of interannual variability, Fig. 7 compares observed and simulated annual averaged precipitation anomalies against the monthly climatology for the 19992008 periods. The correlations between simulated and observed precipitation anomalies are between 0.63 and 0.82 for the CRU and EIN datasets, but not as high compared to UDEL dataset (0.36-0.41). In fact, the UDEL dataset also has a different anomaly pattern than the CRU and raw ERAInterim (EIN) data. It is also shown that all simulations have a very similar annual anomaly pattern. 


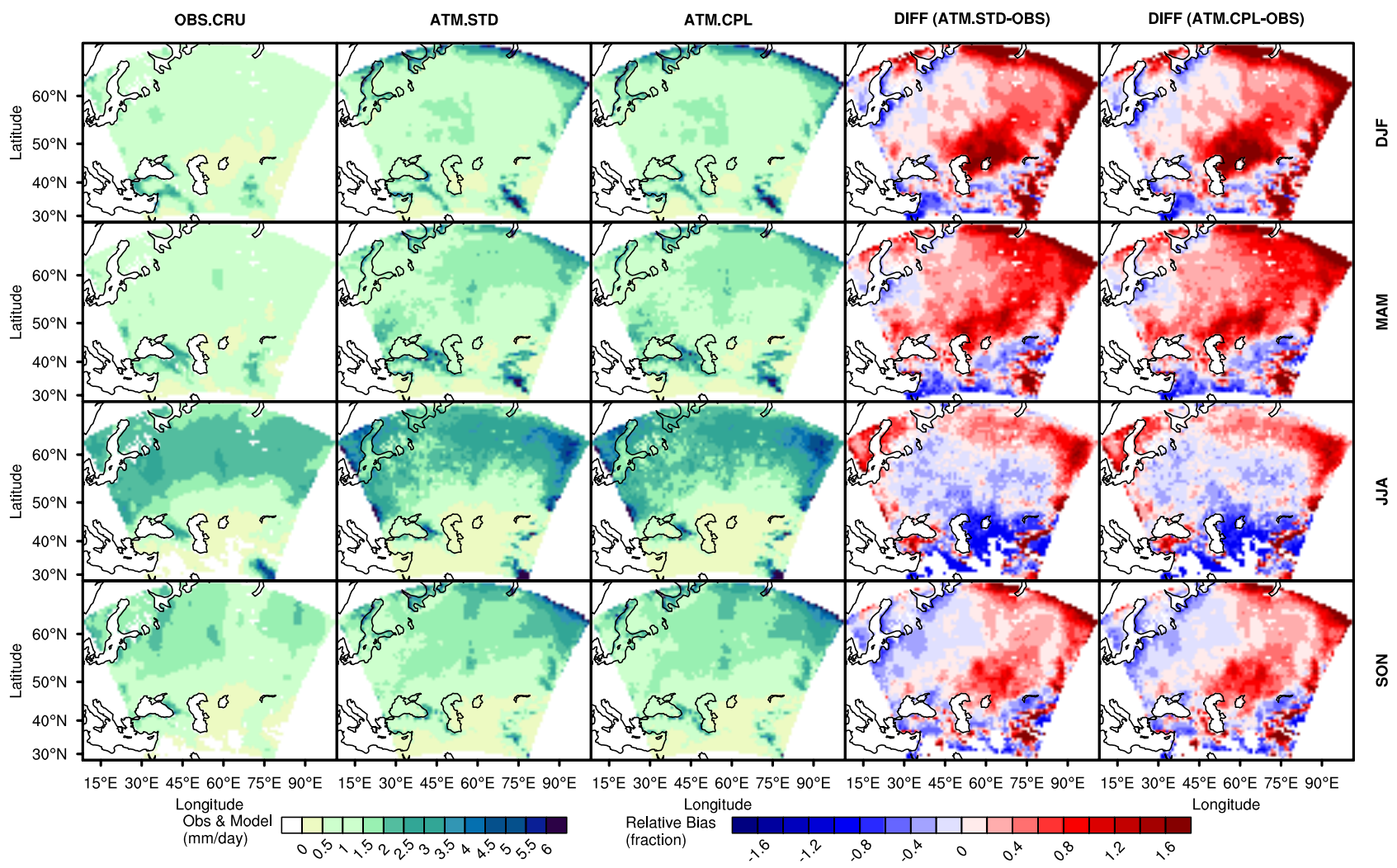

Fig. 6. Seasonal precipitation climatology of ATM.STD, ATM.CPL simulations and observation (CRU version 3.10), along with the corresponding relative biases for the period 1999-2008.

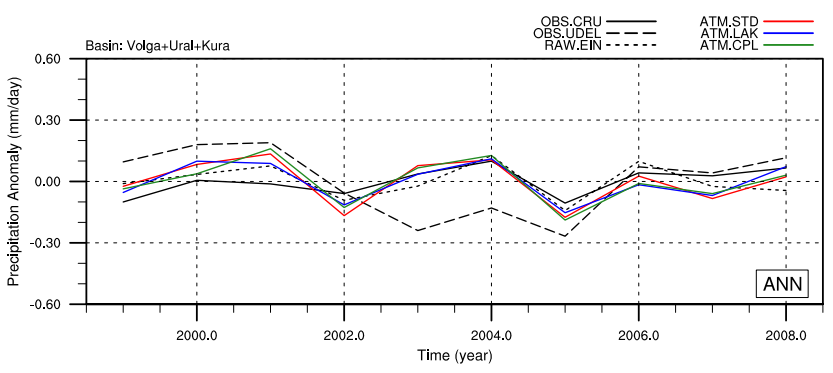

Fig. 7. Anomalies of annual precipitation $\left(\mathrm{mm} \mathrm{day}^{-1}\right)$ for the period 1999-2008 in the model simulations and the different observation datasets. The domain only includes the Volga, Kura and Ural basins shown in Fig. 3 (extracted from the Total Runoff Integrating Pathways, or TRIP, dataset).

In summary, the present model simulations represent well the observed climatology during the analysis period, with results in line with the experiments of Turuncoglu et al. (2012) and with relatively small differences across the different model configurations.

\subsubsection{Ocean temperature and salinity}

Simulated and observed seasonal SST patterns are shown in Fig. 8. We note that there is considerable uncertainty in the observations. Both the Global Ocean Data Assimilation Experiment (GODAE) high-resolution sea surface temperature (GHRSST) and ARCLAKE datasets are based on remotesensing observations, and might have high observational uncertainty, particularly during the winter and fall seasons due to the cloud effects. IIbrayev's climatology (indicated as OBS.CLIM in Fig. 8), which is based on in situ data (CTD, etc.), could also have a high degree of uncertainty during the winter season in the northern Caspian Sea because of the ice coverage there.

The OCN.STD, OCN.CPL and ATM.LAK simulations are able to reproduce the basic SST patterns in all seasons. However, none of the models simulates the upwelling along the eastern coast of the Caspian Sea that occurs during the summer season. This is expected for the ATM.LAK simulation, which uses a one-dimensional lake model to represent the sea, but less so for the OCN.STD simulation, which use a three-dimensional ocean model. The lack of upwelling may, in part, be related to the relatively coarse resolution $(\sim 50 \mathrm{~km})$ of the atmospheric component in the coupled modelling system. Sensitivity tests performed by 


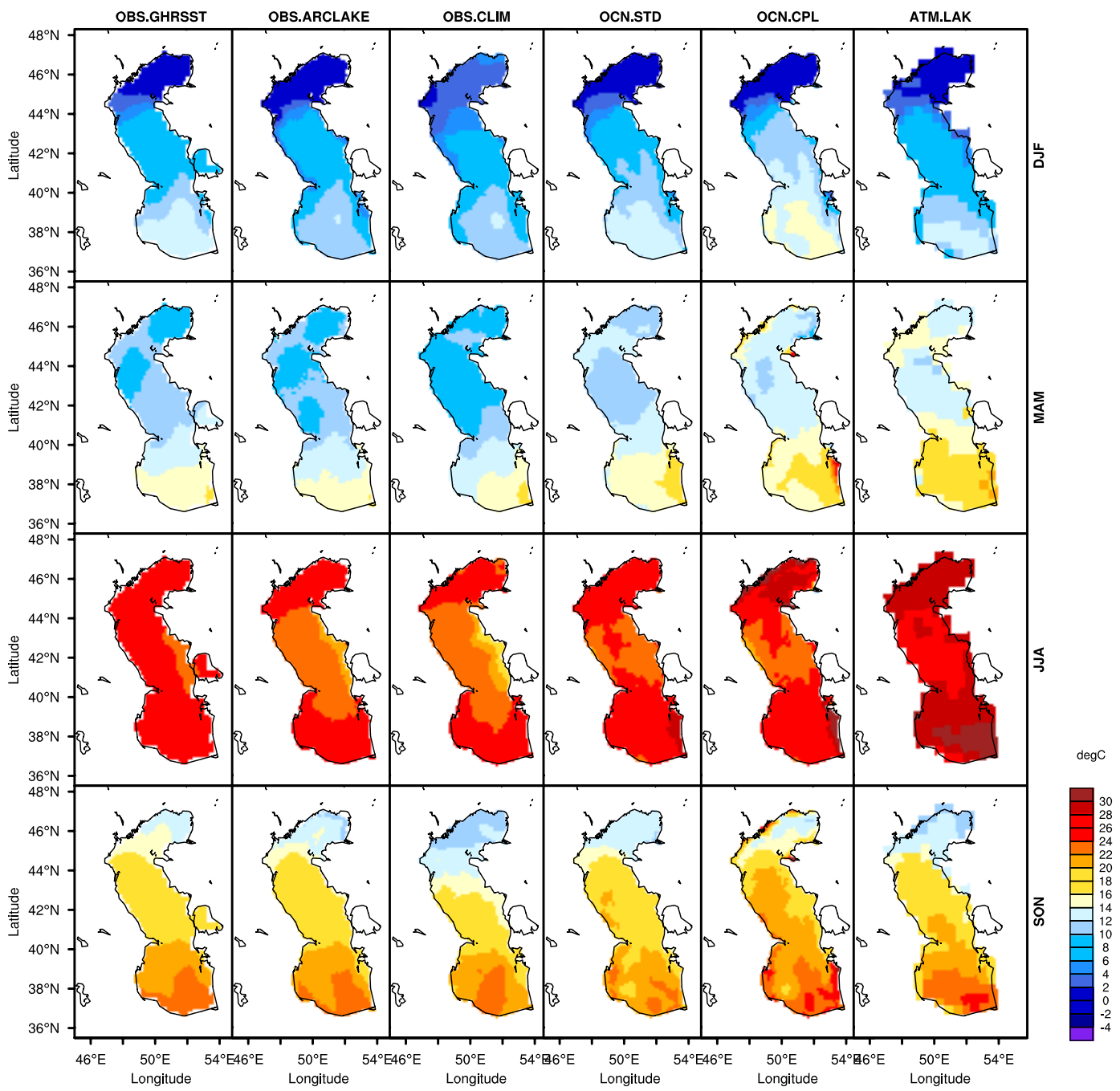

Fig. 8. Seasonal sea surface temperature climatology of OCN.STD, OCN.CPL, ATM.LAK simulations and observations (GHRSST, ARCLAKE and climatology from Ibrayev et al., 2001) for the period 1999-2008.

Turuncoglu et al. (2012) showed that increasing the resolution of the atmospheric model from $50 \mathrm{~km}$ to $20 \mathrm{~km}$ produces wind speeds that are $50 \%$ stronger over the central Caspian Sea (CCAS) during the summer. The ATM.LAK simulation has the largest bias $\left(3.5-4.0^{\circ} \mathrm{C}\right)$, which occurs during the summer and during the spring, especially in the southern and central Caspian Sea (SCAS and CCAS) due to the lack of the heat transport among adjacent grid cells. In general, the OCN.CPL simulation is warmer than the OCN.STD $\left(\sim 0.5-1.0^{\circ} \mathrm{C}\right.$ in NCAS and CCAS $)$, particularly in the winter over the southern Caspian, and spring and fall seasons throughout the lake (Fig. 8). This may be related to nonlinear interactions between the model components and requires additional sensitivity tests with the coupled modelling system. Overall, except for the winter season over the southern Caspian, the use of ROMS appears to clearly improve the simulation of SST compared to the use of the one-dimensional lake model.

Figure 9 compares the observed and simulated (OCN.STD, OCN.CPL and ATM.LAK) mean annual cycle of averaged SST over different regions of the Caspian Sea. All simulations using ROMS reproduce the annual SST pattern well (Fig. 9). Use of the couple lake model (ATM.LAK) leads to an overestimate of SST in the Central and Southern Caspian Sea regions (CCAS and SCAS), particularly in spring and summer (see also Fig. 8). The coupled model is slightly warmer than the stand-alone ROMS, especially in the winter season. Again, overall the use of the three-dimensional ocean model decreases the warm season bias compared to the use of the lake model by up to $4^{\circ} \mathrm{C}$.

Observed and simulated (OCN.STD and OCN.CPL) cross-sectional (E-F, in south-north direction) profiles of 


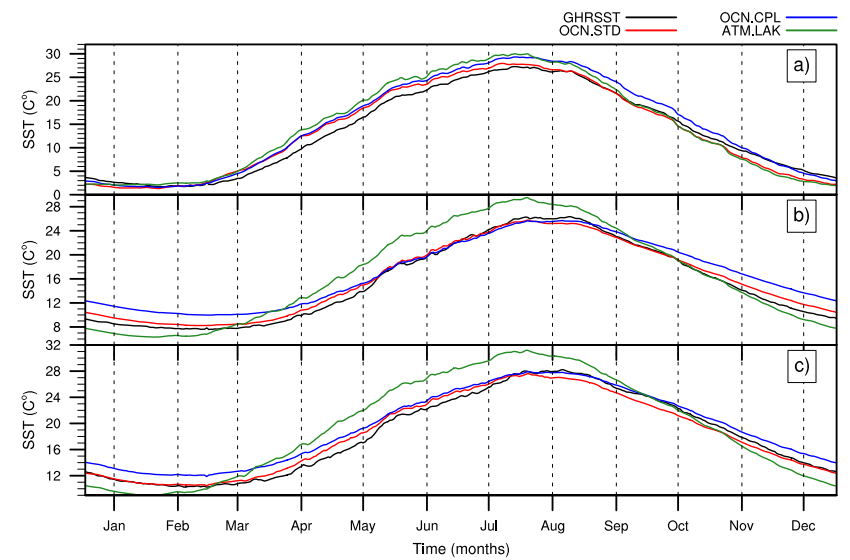

Fig. 9. Time series of daily sea surface temperature (SST) climatology of OCN.STD, OCN.CPL, ATM.LAK simulations and observation (GHRSST) for the period 1999-2008. The order of plots is: (a) Northern Caspian Sea - NCAS, (b) Central Caspian Sea - CAS, and (c) Southern Caspian Sea - SCAS. The sub-regions are shown in Fig. 3b.

seasonal averaged lake temperature are displayed in Fig. 10. Note that the observational data are interpolated to the model grid prior to seasonal averaging and the observed climatology does not represent the same temporal period as the ocean model simulations (see Sect. 2). Both the coupled and uncoupled versions of the ocean model are able to reproduce the main seasonal characteristics of the temperature profile in the cross-section analysed. In winter and fall, the models have warm biases ranging between $1.5-2{ }^{\circ} \mathrm{C}$, in particular, over the CCAS and NCAS regions. Nevertheless, the simulated pattern of the vertical temperature profile is very similar to observations. The temperature in the deepest regions of the sea are overestimated by OCN.STD run, but improved in the coupled model (OCN.CPL). During summer, the strong thermocline which is located between depths of 20 and $50 \mathrm{~m}$ is well reproduced by the models, but shifted slightly upward. The OCN.STD and OCN.CPL models produce a very similar thermal structure during summer, with the exception of the deepest regions of the Sea.

The effects of river discharge on the spatial pattern of sea surface salinity (SSS) is clear (Fig. 11), with low salinity values in the northern shelf of the sea (where the Volga discharge occurs) and high and homogeneous values in the central and southern regions. The comparison of observations (from Ibrayev et al., 2001) and model results (CAS.STD and CAS.CPL) indicates that the largest differences ( 5-6PSU) occur in the northern shelf region due to the Volga river freshwater discharge. Over the rest of the Sea, the SSS varies only between 12 and 13 PSU in both the simulation and observations. In the northern Caspian Sea, salinity ranges from 1 to 5 PSU in the regions close to the coast and gradually becomes saltier $(\sim 10-12$ PSU) towards the interior.

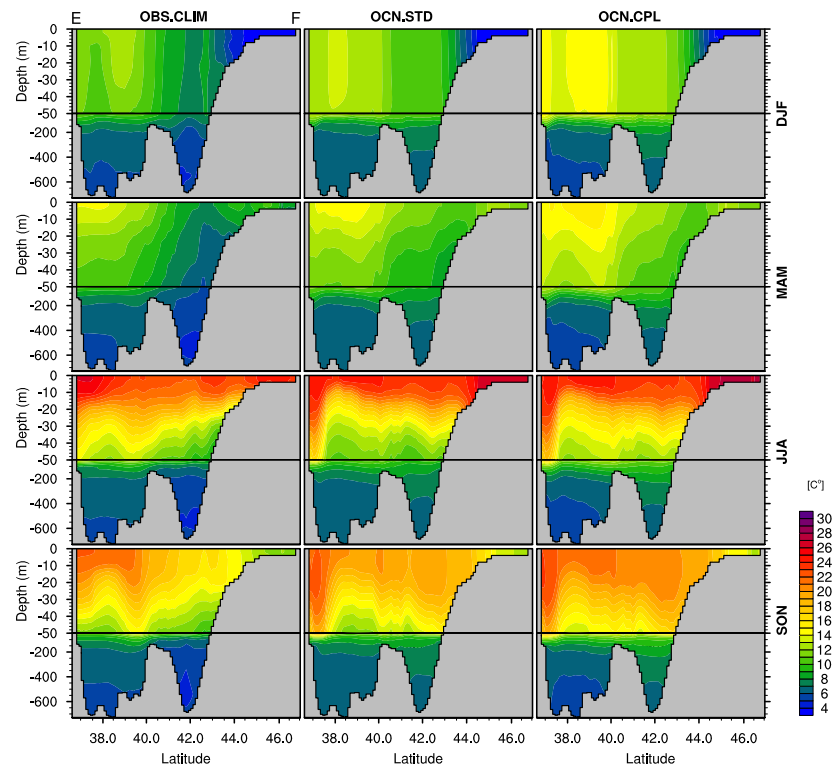

Fig. 10. Vertical cross section (E-F, see Fig. 3b) of seasonal temperature climatology of observation (from Ibrayev et al., 2001) and OCN.STD, OCN.CPL simulations for the period 1999-2008. Also note that the depth axis is not monotonically increasing (zoomed in to first $50 \mathrm{~m}$ ).

The large bias between simulated and observed SSS in the northern region of the sea is in large part related to how inflow from the river is dispersed in the ocean model, especially for the Volga input. In the current version of the model, river discharge is distributed between the first 10-sigma layers with a decreasing weight factor from the top to the bottom layers. As a result, the fresh water input will affect the top most layers more. In future studies, we plan to test the ocean model with different vertical river discharge distribution options. It is also known that the effect of the discharge rate from the Volga River controls the monthly variations in the NCAS (Kara et al., 2010). Additionally, we believe that the observational data might have large uncertainty especially over NCAS during the period of the highest river discharge rate (early Spring). Moreover, the spatial pattern of the simulated SSS is rather similar to the observations indicated by Kosarev and Yablonskaya (1994).

\subsubsection{Sea surface circulation}

The Caspian Sea currents are mainly driven by wind, but baroclinic currents also play an important role for local circulation patterns (Sur et al., 2000). The combination of winddriven and baroclinic currents create a wide range of currents, both temporally and spatially, however, the main characteristics of the surface ocean circulation is defined as cyclonic (counter-clockwise).

Seasonal means of sea surface currents (speed and direction) from the OCN.CPL simulation are presented in Fig. 12. 


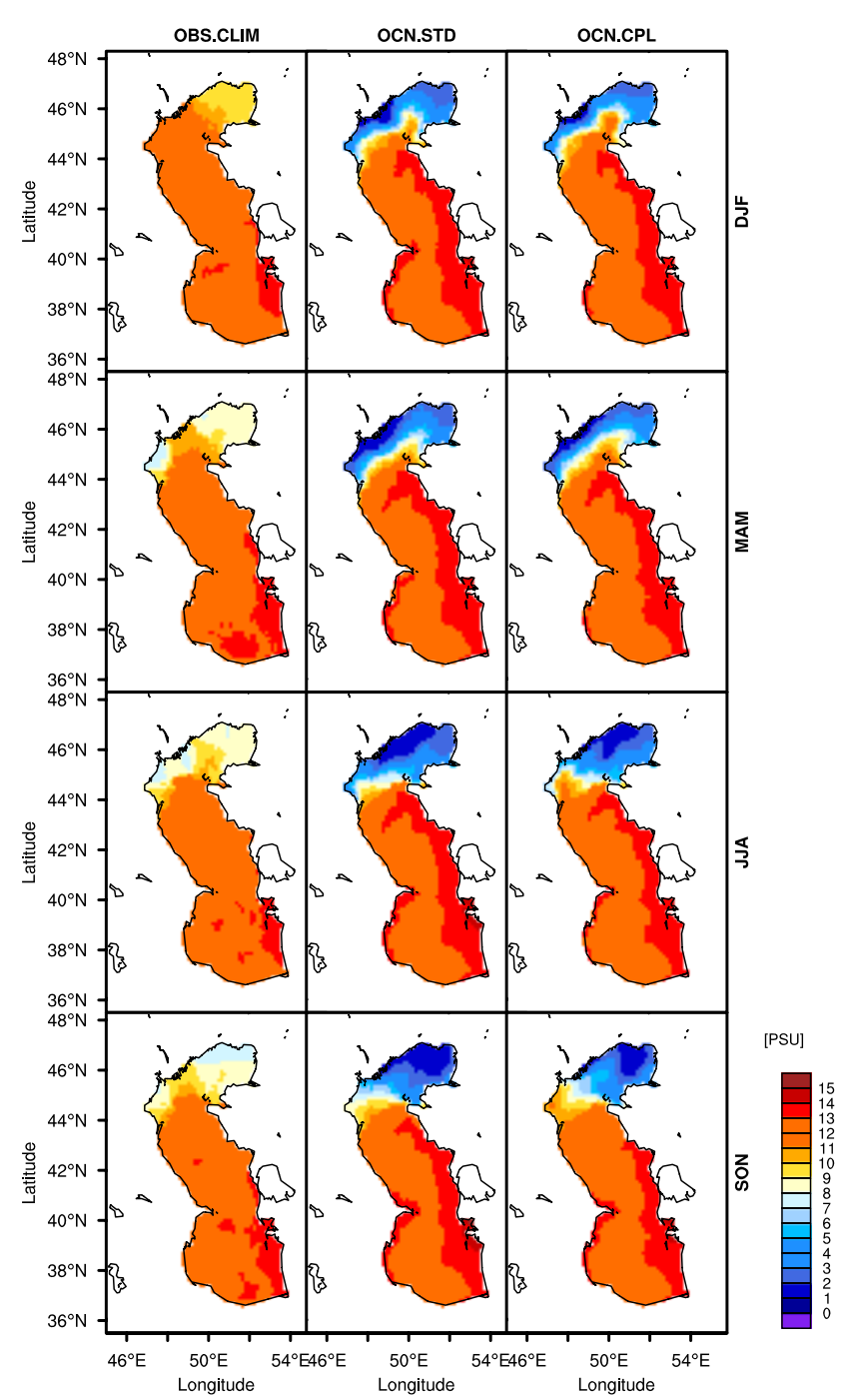

Fig. 11. Seasonal sea surface salinity (SSS) climatology of simulations (OCN.STD and OCN.CPL) and observation (from Ibrayev et al., 2001) for the period 1999-2008.

The OCN.STD simulation results are not shown here because of the similarity with the coupled model. In winter and spring, north-south direction currents develop along the western coast of the CCAS region and extend through the southern part of the basin (SCAS) with increasing speed (18$24 \mathrm{~cm} \mathrm{~s}^{-1}$ ), consistent with the results of Kosarev's (1994). The cyclonic gyre in the SCAS region continues to intensify $\left(>24 \mathrm{~cm} \mathrm{~s}^{-1}\right)$ during summer and fall. The northward currents start to develop in winter along the eastern coast of the sea and intensify to reach speeds of up to $12-16 \mathrm{~cm} \mathrm{~s}^{-1}$ in fall. In general, the northward current along the eastern coast of the sea is associated with upwelling along the coast in summer, however, this is not strong in the models (see Sect. 3.4.2 and Fig. 8) probably because of the underestimation of the surface wind speed associated with the relatively low resolution of the atmospheric component. During winter and spring, small-scale, weak cyclonic gyres can be seen

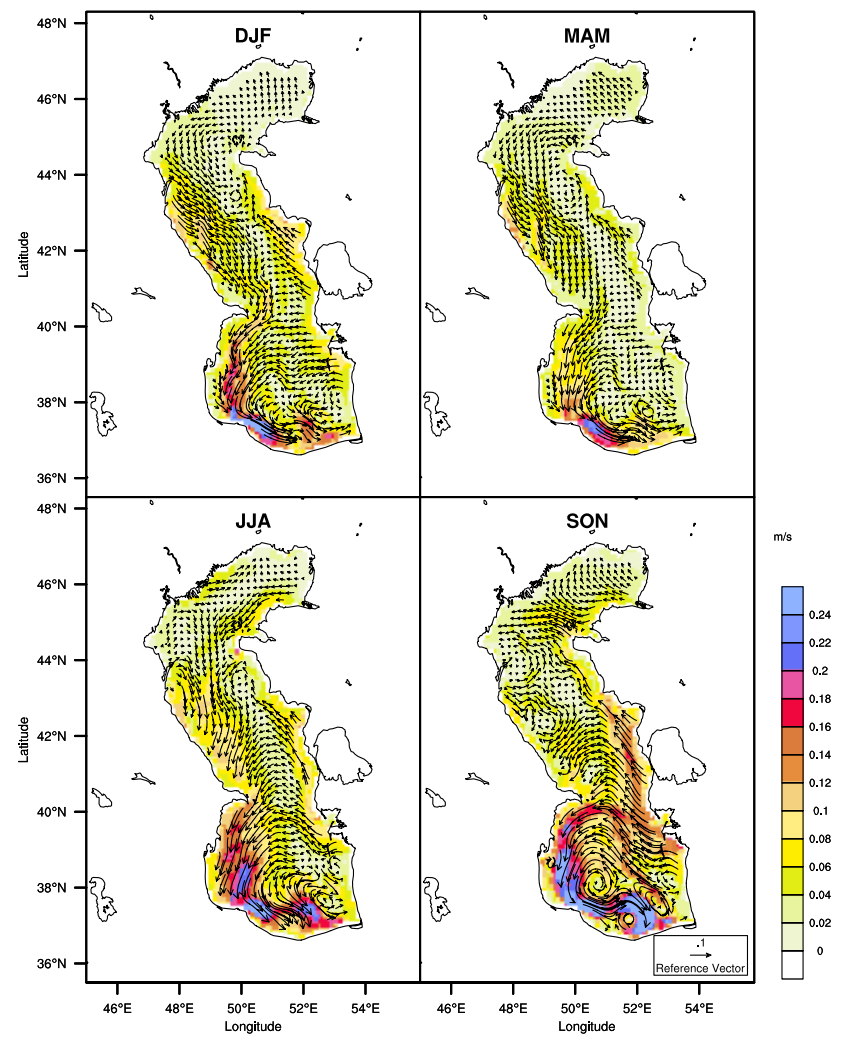

Fig. 12. Seasonal sea surface currents climatology of OCN.STD, OCN.CPL simulations for the period 1999-2008.

over NCAS but are not persistent. This could be related to the modified minimum depth, which is set as $5 \mathrm{~m}$ in the shallow regions of the NCAS region to prevent the pressure-gradient error.

Overall, these results are consistent with previous work (Kosarev and Yablonskaya, 1994; Sur et al., 2000; Kara et al., 2010), and show that the coupled modelling system is able to reproduce the main characteristics of the Sea's surface currents.

\subsubsection{Evaporation, water budget and caspian sea level}

In this section, we compare simulated evaporation over the sea with Objectively Analysed air-sea Fluxes (OAFlux) gridded observations (Yu et al., 2008), which has a $1^{\circ} \times 1^{\circ}$ spatial resolution and is available at both daily (1985-2012) and monthly (1958-2012) temporal resolutions. Although the dataset is designed for the global oceans, it also includes data over the Caspian Sea. OAFlux is developed from satellite microwave radiometers and validated against in situ flux measurements, however, the data have not been validated over the Caspian Sea, thus, caution should be taken when assessing the results. In addition, the observations are not considered reliable within $75 \mathrm{~km}$ of the coastlines or over the NCAS region due to the lack of sea-ice mask (Yu et al., 2008). 


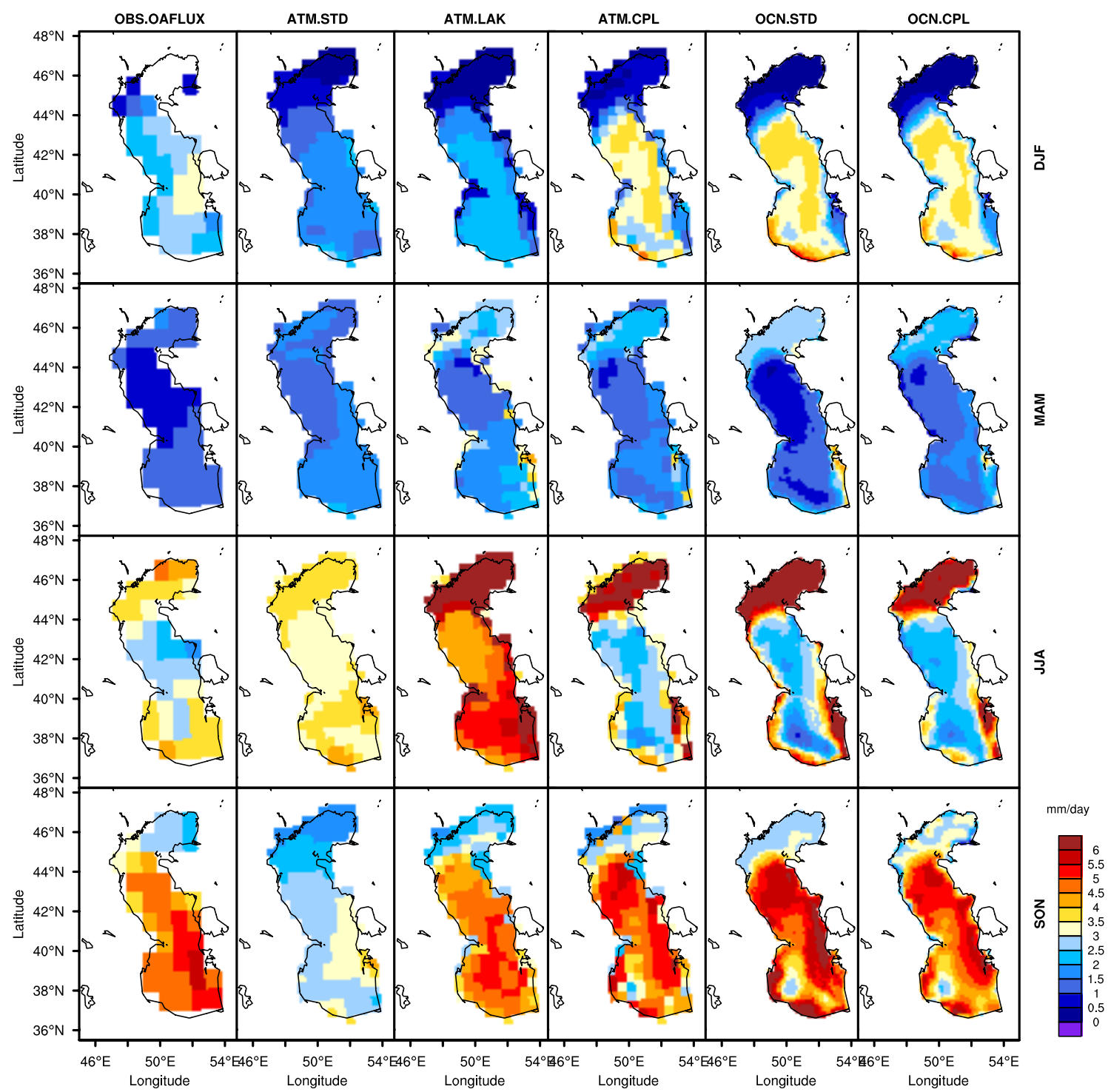

Fig. 13. Seasonal sea surface evaporation climatology of simulations and observation (Objectively Analysed air-sea Fluxes OAFlux for Global Oceans) for the period 1999-2008.

Simulated and observed seasonal evaporation over the Sea are shown in Fig. 13. In winter, the ATM.CPL and OCN.CPL overestimate evaporation in the CCAS region with a bias of $1.0 \mathrm{~mm} \mathrm{day}^{-1}$, while in summer the evaporation bias is positive in the NCAS and negative in the SCAS. The agreement between models and observations is generally good in the intermediate seasons (MAM and SON). The standalone atmospheric model (ATM.STD) underestimates evaporation (1.5-2.0 mm day $\left.{ }^{-1}\right)$ in fall and winter, while it tends to overestimate it in summer. The coupled lake simulation also shows a noticeable positive bias in the summer. Overall the coupled model results and the OCN.STD shows the best agreement with observations, indicating that use of ROMS tends to improve the simulation of evaporation.
Figure 14 shows a time series of simulated and observed evaporation averaged over the Sea for the period of 19992008. All of the simulations reproduce the seasonal pattern of the evaporation, with a maximum in the fall and minimum in the spring. Correlations range from 0.73 for ATM.STD and ATM.LAK to 0.95 for the coupled models. The only simulation that substantially deviates from observations on a lakewide basis is ATM.STD, particularly in the season of maximum evaporation. The summer overestimate by ATM.LAK is also evident from Fig. 14. Thus, it appears that use of the three dimensional ocean model, both in coupled and uncoupled mode, is important for a correct simulation of evaporation from the Caspian sea.

As mentioned above, the CSL varies considerably on monthly, seasonal, annual and decadal time scales in 


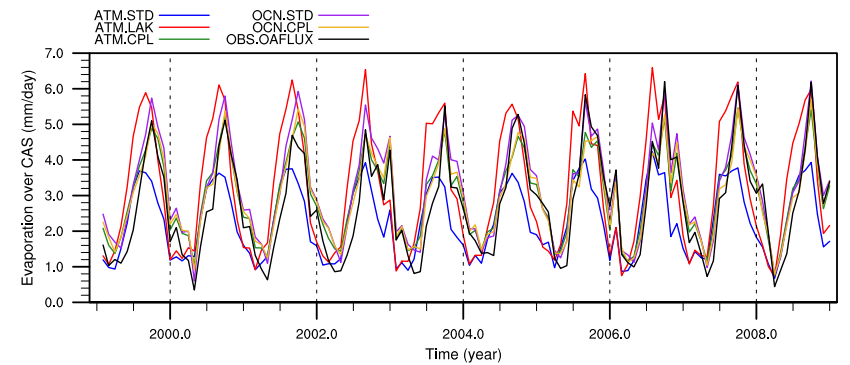

Fig. 14. Time series of monthly evaporation $\left(\mathrm{mm} \mathrm{day}^{-1}\right)$ over CAS of modelled and observed (OAFlux) for the period 1999-2008.

response to the basin's water budget, comprised of evaporation $(E)$ and precipitation $(P)$ over the Sea, and river discharge $(R)$. As a result, one of the most important problems in modelling a closed basin like the Caspian Sea is in accurately estimating the water balance of the basin. In particular, any of the hydrological components $(P, E$ or $R)$ can affect both the dynamic and physical behaviour of the ocean model, especially in shallow regions such as NCAS. If the depth becomes unrealistically shallow, then the model can produce artificial ice, which will affect thermal and dynamic processes in the region.

In order to evaluate the performance of the coupled model in simulating the basin's water balance, time series of variations in the monthly CSL (extracted from sea surface height field of the ocean model) are presented in Fig. 15. Modelled CSL are compared to available altimetry data from GRLM altimetry data for the period 1996-2008. The coupled model simulation (ATM.CPL) in good agreement with observations in simulating the seasonal variability of the CSL. However, the interannual variability has a decreasing trend, which may be due to a combination of several factors. Firstly, the observed river discharge data were measured a couple of hundred kilometres upstream of the entry points, thus, correction factors were applied to the data to account for subsequent water losses such as evaporation. Secondly, although it is difficult to evaluate due to the high level of uncertainty in the data, an overestimate in coupled model's evaporation over the Sea probably contributes to the CSL's decreasing trend. Namely, the model overestimates evaporation during the winter in the CCAS region and during the summer in the NCAS region. In view of the uncertainties mentioned above, more analysis is needed to fully evaluate the potential of the coupled ROMS to directly estimate CSL variations.

\subsubsection{Surface radiative and energy flux components of the sea}

To extend our analysis and evaluate the model heat budget over the sea, monthly and annual lake-averaged energy flux components are given in Table 2 . We only present results from the ATM.CPL simulation in the table to provide a clearer overview of the heat flux components.

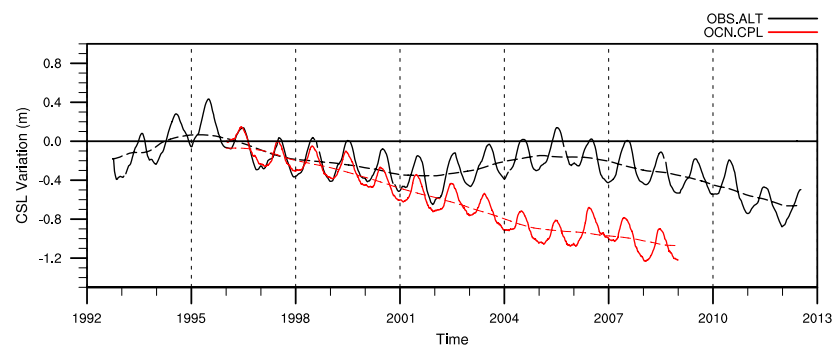

Fig. 15. Time series of monthly Caspian Sea Level (CSL) variation $(\mathrm{m})$ of modeled (ATM.STD, ATM.LAK and ATM.CPL) and observed (altimetry data from GRLM project) for the period 19952008. The dashed lines represent the 3-yr running averages to show the inter-annual variability.

The total radiative flux ranges from $-15 \mathrm{~W} \mathrm{~m}^{-2}$ in December to $228 \mathrm{~W} \mathrm{~m}^{-2}$ in June (Table 2), while the sensible heat flux is negative (heat loss) in the winter months $\left(\sim-38 \mathrm{~W} \mathrm{~m}^{-2}\right)$ and slightly positive $\left(\right.$ a few $\left.\mathrm{W} \mathrm{m}^{-2}\right)$ in the summer ones. The heat loss due to latent heat release peaks in September $\left(\sim-141 \mathrm{~W} \mathrm{~m}^{-2}\right)$ and is minimum in the spring $\left(\sim-40 \mathrm{~W} \mathrm{~m}^{-2}\right)$. The resulting simulated total energy budget for the Sea shows a positive maximum in May and June $(\sim$ $\left.140 \mathrm{~W} \mathrm{~m}^{-2}\right)$ and a minimum in December $\left(\sim-137 \mathrm{~W} \mathrm{~m}^{-2}\right)$. On an annual basis the sensible and latent heat losses balance rather closely with the radiative energy input.

Also shown in Table 2 are mean annual flux values from Ibrayev et al. (2010), which where calculated with the use of a three-dimensional ocean model forced by observed meteorological data. Compared to Ibrayev et al. (2010) our coupled modelling system produces a larger solar energy input (by about $27 \mathrm{~W} \mathrm{~m}^{-2}$ ), which is mostly balanced by a greater evaporative loss. This might be due to an underestimate of cloudiness over the sea, which would be consistent with the comparison (see Fig. 16) with the International Satellite Cloud Climatology Project (ISCPP) D2 product (Schiffer and Rossow, 1983; Rossow and Schiffer, 1999). The horizontal resolution of ISCPP-D2 monthly mean data is $280 \mathrm{~km}$. As can be seen from the figure, all of the simulations capture the observed seasonal cloudiness cycle and have correlations which are around 0.91, however, the models have a significant negative bias, producing \% 10-20 less cloud cover than the observational data.

\subsubsection{Sea ice}

The seasonal ice coverage patterns for the simulations and observations are shown in Fig. 17. The spatial extent of ice coverage is well simulated in both the OCN.STD and OCN.CPL simulations. Both models underestimate the fraction of ice coverage, which is related to ice thickness, with the coupled model performing slightly better. The underestimation could in part be related to the pre-defined minimum depth $(5 \mathrm{~m})$ in the ROMS ocean model, used to prevent 
Table 2. Lake averaged monthly mean heat flux components $\left(\mathrm{W} \mathrm{m}^{-2}\right)$ at the sea surface for the period 1996-2008 from the ATM.CPL simulation. The $Q_{\mathrm{s}}=$ incoming solar radiation, $Q_{\mathrm{b}}=$ (long wave) thermal radiation, $Q_{\mathrm{s}}+Q_{\mathrm{b}}=$ total radiative heat flux, $H=$ sensible heat flux, $\mathrm{LE}=$ latent heat flux, $Q=$ total heat flux. Annual mean (indicated by star symbol) are values reported by Ibrayev et al. (2010).

\begin{tabular}{lrrrrrr}
\hline Month & $Q_{\mathrm{s}}$ & $Q_{\mathrm{b}}$ & $Q_{\mathrm{s}}+Q_{\mathrm{b}}$ & $H$ & $\mathrm{LE}$ & $Q$ \\
\hline January & 70.04 & -77.31 & -7.27 & -38.69 & -67.91 & -113.88 \\
February & 105.94 & -77.17 & 28.77 & -26.24 & -55.36 & -52.83 \\
March & 163.50 & -73.41 & 90.09 & -7.18 & -40.89 & 42.02 \\
April & 224.72 & -72.00 & 152.72 & -1.26 & -40.25 & 111.20 \\
May & 286.96 & -83.01 & 203.96 & -0.68 & -62.79 & 140.49 \\
June & 317.49 & -89.04 & 228.45 & 2.51 & -93.72 & 137.24 \\
July & 307.62 & -86.82 & 220.80 & 4.80 & -109.15 & 116.44 \\
August & 275.74 & -93.23 & 182.51 & 1.90 & -129.69 & 54.72 \\
September & 211.25 & -93.64 & 117.61 & -12.85 & -141.34 & -36.58 \\
October & 135.69 & -85.01 & 50.68 & -24.98 & -113.86 & -88.16 \\
November & 84.90 & -81.69 & 3.21 & -38.50 & -98.64 & -133.93 \\
December & 63.87 & -79.00 & -15.13 & -39.92 & -82.30 & -137.35 \\
Annual Mean & 187.31 & -82.61 & 104.70 & -15.09 & -86.36 & 3.25 \\
Annual Mean* & 160.40 & -79.80 & 80.60 & -10.40 & -69.90 & 0.30 \\
\hline
\end{tabular}

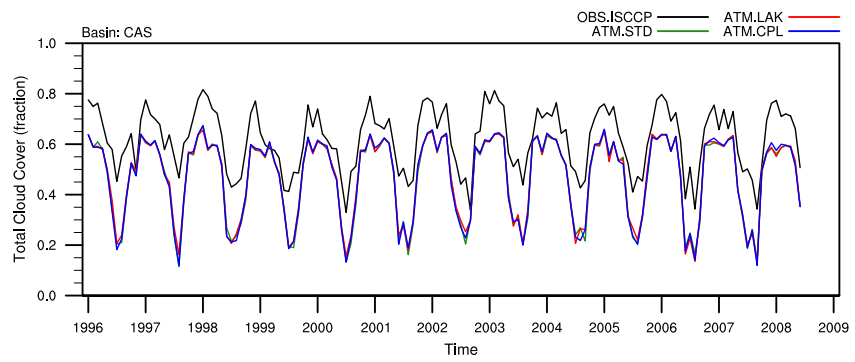

Fig. 16. Time series of monthly total cloud cover (fraction) of modelled (ATM.STD, ATM.LAK and ATM.CPL) and observed (ISCPP project D2 product) for the period 1996-2008.

instability problems. However, the northern shelf of the sea is quite shallow, often less than $5 \mathrm{~m}$. Sensitivity tests have shown that ice coverage and thickness strongly depend on the bathymetry in the northern Caspian Sea (Kouraev et al., 2004) and this, at least, partially explains the model underestimate of ice fraction. The results also show that the OCN.CPL simulation improves the ice coverage along the north coast of the sea and also some interior regions. In general, the coupling appears to improve the simulation of the spatial structure of ice cover.

Figure 18 compares the simulated seasonal evolution of averaged ice cover over NCAS region in three simulations (OCN.STD, OCN.CPL and ATM.LAK). On average, ice formation starts in mid-November in the very shallow regions in the NCAS, but can form as early as October during severe winters and as late as the end of December or early January in warm year (Kouraev et al., 2004). Ice cover peaks in late January, early February and typically starts to decrease in March, until the entire region (NCAS) will be ice-free by end of April (Kouraev et al., 2004).
In both the ATM.LAK and OCN.STD simulations, ice formation begins at the beginning of December, while in the OCN.CPL simulation some ice is found earlier in midNovember (Fig. 18). In ATM.LAK and OCN.CPL, the ice is completely melted by the end of March, while full melting occurs by mid-March in the OCN.STD run. These results are consistent with the observations given in Kouraev et al. (2004). The averaged ice thickness peaks in late January, but varies among the models, with an earlier peak when using ROMS than in ATM.LAK. The OCN.CPL model produces the thickest average ice (peaks at $160 \mathrm{~mm}$ ), followed by the OCN.STD model (peaks at $140 \mathrm{~mm}$ ), and finally the ATM.LAK model (peak $<120 \mathrm{~mm}$ ). The maximum ice thickness over NCAS region in the OCN.CPL, OCN.STD and ATM.LAK models are 376, 347 and $319 \mathrm{~mm}$, respectively. Kouraev et al. (2004) reports this value to be between 400 and $500 \mathrm{~mm}$, confirming that the OCN.CPL model produces the most realistic, albeit still somewhat underestimated ice cover.

\section{Summary and conclusions}

This study describes the implementation of a newly designed coupled regional atmosphere-ocean modelling system (RegCM4-ROMS), with specific application to the Caspian Sea region. Results from different model configurations are compared to a wide variety of available observational data. The analysis aims to show the overall performance of the coupled modelling system (components are ATM.CPL and OCN.CPL) with respect to stand-alone versions (ATM.STD, OCN.STD) of the sub-model components and a coupled model setup using a one-dimensional lake model (ATM.LAK). 


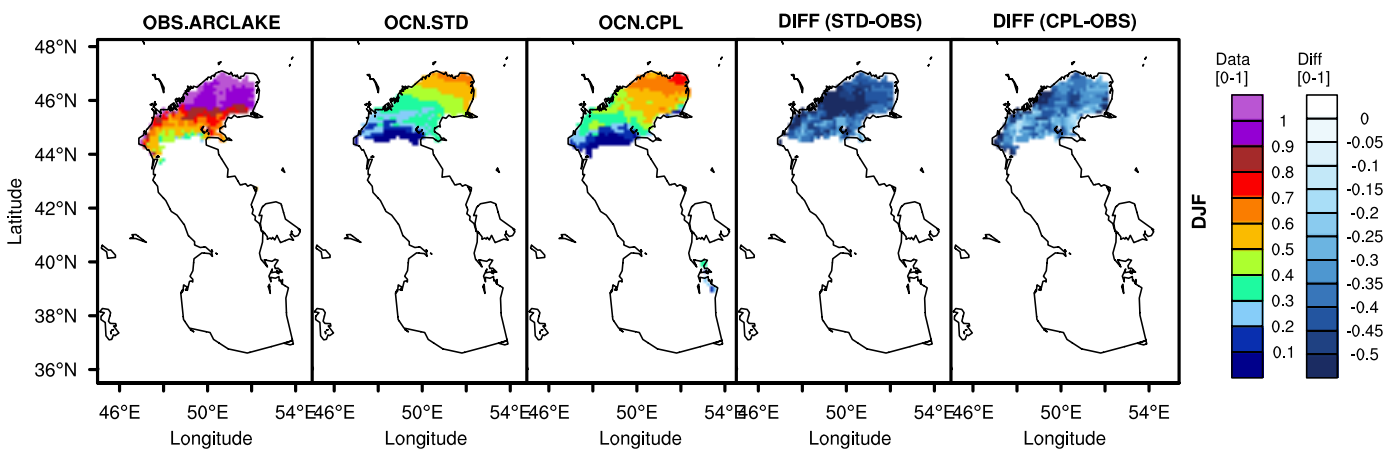

Fig. 17. DJF season climatology of lake ice coverage for the period 1999-2008 in ARCLAKE observation (fraction), OCN.STD and OCN.LAK (fraction) simulations. Values lower than 0.01 are masked out.

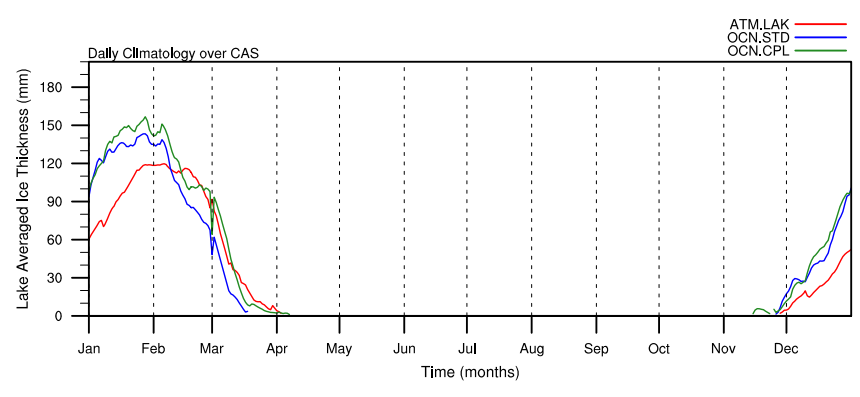

Fig. 18. Time series of daily sea ice climatology of OCN.STD and OCN.CPL simulations and observation (ARCLAKE) for the period 1999-2008.

All the different model versions realistically simulate the basic characteristics of the climatology of the region, with relatively small differences across experiments. Larger sensitivities are found when looking at lake variables. The ocean model component (ROMS) reproduces quite accurately the observed lake-average SST, both in the coupled and uncoupled runs, except for the upwelling region along the eastern shore of the sea. The vertical temperature and salinity profiles as well as the surface circulation are also realistically simulated, although upwelling in the eastward coastal regions of the sea is underestimated. Sea ice extent and seasonal evolution in the shallow north basin of the Sea is also realistically simulated, although the sea ice depth is somewhat underestimated compared to ARCLAKE observations, likely due to the use of a minimum depth of $5 \mathrm{~m}$ in the model (introduced for stability purposes).

Evaporation over the sea is an important component of the hydrological balance estimation of the Sea. In general, the model produces evaporation values consistent with observations, although some seasonal biases are found. The overall energy budget is consistent with that produced by Ibrayev et al. (2010), although the solar input and evaporation losses are higher than in that study. This excessive lake evaporation leads to a drift in the CSL calculated by ROMS, a result that requires more in depth analysis due to many un- certainties in the estimation of the CSL. Intercomparison of the different experiments indicates that use of ROMS substantially improves the simulation of lake variables compared to the one-dimensional distributed lake model, while the interactive coupling provides only some limited improvements compared to running ROMS stand-alone. Overall, the coupled model exhibits a satisfactory performance in reproducing observed climate and sea variables for the Caspian Sea region, particularly concerning the basin-wide energy and hydrologic budget, which is most important for calculating the response of the CSL to climate variability and change. In the future, we plan to extend the capability of the coupled modelling system by adding a simple river routing scheme to convert atmospheric model runoff information into river discharge. This will allow the atmosphere and ocean model components to be more tightly integrated and will enable us to perform future scenario simulations. We also plan to increase the atmospheric model resolution to provide better wind forcing to the ocean model component and provide finer scale climate information. For this work, the coupled modelling system employed the BATS land surface scheme, but more testing of the CLM land model is under way and will allow better representation of the surface hydrologic cycle of the basin.

\section{Supplementary material related to this article is available online at: http://www.geosci-model-dev.net/6/ 283/2013/gmd-6-283-2013-supplement.pdf.}

Acknowledgements. The authors wish to thank Robin Wardlaw and Andrew Shalygin for providing the river runoff data. We also wish to thank Alan J. Wallcraft from Oceanography Division, Naval Research Laboratory, Stennis Space Centre, MS, USA for providing Caspian Sea climatology data and Kate Hedstrom from ARSC, U. of Alaska Fairbanks for sharing her experience about ROMS-Ice model.

Edited by: R. Redler 


\section{References}

Adam, J. C. and Lettenmaier, D. P.: Adjustment of global gridded precipitation for systematic bias, J. Geophys. Res., 108, 4257, doi:10.1029/2002JD002499, 2003.

Amante, C. and Eakins, B. W.: ETOPO1 1 Arc-Minute Global Relief Model: Procedures, Data Sources and Analysis, NOAA Technical Memorandum NESDIS NGDC-24, 19 pp., 2009.

Anisimov, O. A., Borzenkova, I. I., Zhil'tsova, E. L., Zakharova, O. K., Kokorev, V. A., Reneva, S. A., and Strel'chenko, Yu. G.: Hydrometeorological Conditions of the Volga Region and Current Climate Changes, Russ. Meteorol. Hydrol., 36, 307-314, 2011.

Anyah, R. O. and Semazzi, F. H. M.: Simulation of the sensitivity of Lake Victoria basin climate to lake surface temperatures, Theor. Appl. Climatol., 79, 55-69, 2004.

Anyah, R. O., Semazzi, F. H. M., and Xie, L.: Simulated Physical Mechanisms Associated with Climate Variability over Lake Victoria Basin in East Africa, Mon. Weather Rev., 134, 3588-3609, 2006.

Arpe, K. and Leroy, S. A.: The caspian sea level forced by the atmospheric circulation, as observed and modelled, Quatern. Int., 173-174, 144-152, 2007.

Arpe, K., Bengtsson, L., Golitsyn, G. S., Mokhov, I. I., Semenov, V. A., and Sporyshev, P. V.: Connection between Caspian sea level variability and ENSO, Geophys. Res. Lett., 27, 2693-2696, 2000.

Bates, G. T., Giorgi, F., and Hostetler, S. W.: Toward the simulation of the effects of the Great Lakes on regional climate, Mon. Weather Rev., 121, 1373-1387, 1993.

Bates, G. T., Hostetler, S. W., and Giorgi, F.: Two-year simulation of the Great Lakes region with a coupled modeling system, Mon. Weather Rev., 123, 1505-1522, 1995.

Bettencourt, M. T.: Distributed model coupling framework, in: Proceedings of the 11th IEEE Symposium on High Performance Distributed Computing, Edinburgh, UK, 23-26 July 2002, 284290, 2002

Budgell, W. P.: Numerical simulation of ice-ocean variability in the barents sea region: Towards dynamical downscaling, Ocean Dynam., 55, 370-387, 2005.

Casulli, V. and Cheng, R.: Semi-implicit finite difference methods for three-dimensional shallow water flow, Int. J. Numer. Meth. Fl., 15, 629-648, 1992.

Collins, N., Theurich, G., Deluca, C., Suarez, M., Trayanov, A., Balaji, V., Li, P., Yang, W., Hill, C., and Da Silva, A.: Design and implementation of components in the Earth System Modeling Framework, Int. J. High Perform. C., 19, 341-350, 2005.

Dee, D. P., Uppala, S. M., Simmons, A. J., Berrisford, P., Poli, P., Kobayashi, S., Andrae, U., Balmaseda, M. A., Balsamo, G., Bauer, P., Bechtold, P., Beljaars, A. C. M., van de Berg, L., Bidlot, J., Bormann, N., Delsol, C., Dragani, R., Fuentes, M., Geer, A. J., Haimberger, L., Healy, S. B., Hersbach, H., Holm, E. V., Isaksen, L., Kallberg, P., Köhler, M., Matricardi, M., McNally, A. P., Monge-Sanz, B. M., Morcrette, J.-J., Park, B.-K., Peubey, C., de Rosnay, P., Tavolato, C., Thepaut, J.-N., and Vitart, F.: The ERA-Interim reanalysis: configuration and performance of the data assimilation system, Q. J. Roy. Meteor. Soc., 137, 553-597, 2011.

Dickinson, R. E., Errico, R. M., Giorgi, F., and Bates, G. T.: A regional climate model for the western United States, Climatic Change, 15, 383-422, 1989.
Elguindi, N. and Giorgi, F.: Simulating multi-decadal variability of Caspian Sea level changes using regional climate model outputs, Clim. Dynam., 26, 167-181, 2006a.

Elguindi, N. and Giorgi, F.: Projected changes in the Caspian Sea level for the 21 st century based on the latest AOGCM simulations, Geophys. Res. Lett., 33, L08706, doi:10.1029/2006GL025943, 2006b.

Elguindi, N. and Giorgi, F.: Simulating future Caspian sea level changes using regional climate model outputs, Clim. Dynam., 28, 365-379, 2007.

Elguindi, N., Somot, S., Déqué, M., and Ludwig, W.: Climate change evolution of the hydrological balance of the Mediterranean, Black and Caspian Seas: impact of climate model resolution, Clim. Dynam., 36, 205-228, 2011.

Georgievsky, V. Yu., Tsytsenko, K. V., and Shalygin, A. L.: Assessment of the rivers inflow to the Caspian Sea, in: Hydrometeorological Aspects of the Caspian Sea and its Basin, SPb, Hydrometeoizdat, Russia, 217-229, 2003.

Giorgi, F., Coppola, E., Solmon, F., Mariotti, L., Sylla, M. B., Bi, X., Elguindi, N., Diro, G. T., Nair, V., Giuliani, G., Turuncoglu, U. U., Cozzini, S., Guttler, I., O'Brien, T. A., Tawfik, A. B., Shalaby, A., Zakey, A. S., Steiner, A. L., Stordal, F., Sloan, L. C., and Brankovic, C.: RegCM4: model description and preliminary tests over multiple CORDEX domains, Climate Res., 52, 7-29, 2012.

Golitsyn, G. S., Meleshko, V., Mesherskaia, A., Mokhov, I., Pavlova, T., Galin, V., and Senatorsky, A.: GCM simulation of water balance over caspian sea and its watershed (Diagnostic Subproject 24), First International AMIP Scientific Conference, Monterey, California, 15-19 May 1995, WMO/TD-No 732, 1519, 1995.

Grell, G. A.: Prognostic Evaluation of Assumptions Used by Cumulus Parameterizations, Mon. Weather Rev., 121, 764-787, 1993.

Grell, G., Dudhia, J., and Stauffer, D. R.: A description of the fifthgeneration Penn State/NCAR mesoscale model (MM5), Technical Note NCAR/TN-398+STR, NCAR, 117 pp., 1995.

Haidvogel, D. B., Arango, H. G., Budgell, W. P., Cornuelle, B. D., Curchitser, E., DiLorenzo, E., Fennel, K., Geyer, W. R., Hermann, A. J., Lanerolle, L., Levin, J., McWilliams, J. C., Miller, A. J., Moore, A. M., Powell, T. M., Shchepetkin, A. F., Sherwood, C. R., Signell, R. P., Warner, J. C., and Wilkin, J.: Ocean forecasting in terrain-following coordinates: formulation and skill assessment of the Regional Ocean Modeling System, J. Comput. Phys., 227, 3595-3624, 2008.

Hill, C., DeLuca, C., Balaji, V., Suarez, M., and Da Silva, A.: The architecture of the Earth System Modeling Framework, Comput. Sci. Eng., 6, 18-28, 2004a.

Hill, C., DeLuca, C., Balaji, V., Suarez, M., Da Silva, A., Sawyer, W., Cruz, C., Trayanov, A., Zaslavsky, L., Hallberg, R., Boville, B. A., Craig, A., Collins, N., Kluzek, E., Michalakes, J., Neckels, D., Schwab, E., Smithline, S., Wolfe, J., Iredell, M., Yang, W., Jacob, L. R., and Larson, J. W.: Implementing Applications with the Earth System Modeling Framework, Lect. Notes Comput. Sci., 3732, 563-572, 2004b.

Holtslag, A. A. M., De Bruin, E. I. F., and Pan, H. L.: A high resolution air mass transformation model for short range weather forecasting, Mon. Weather Rev., 118, 1561-1575, 1990.

Hostetler, S. W., Bates, G. T., and Giorgi, F.: Interactive Coupling of a Lake Thermal Model with a Regional Climate Model, J. Geophys. Res, 98, 5045-5057, 1993. 
Hunke, E. C.: Viscous-plastic sea ice dynamics with the evp model: linearization issues, J. Comp. Phys., 170, 18-38, 2001.

Hunke, E. C. and Dukowicz, J. K.: An elastic-viscous-plastic model for sea ice dynamics, J. Phys. Oceanogr., 27, 1849-1868, 1997.

Ibrayev, R. A., Sarkisyan, A. S., and Trukhchev, D. I.: Seasonal variability of the circulation of the Caspian Sea reconstructed from normal hydrological data, Izv. Atmos. Ocean. Phys., 37, 96-104, 2001.

Ibrayev, R. A., Özsoy, E., Schrum, C., and Sur, H. I.: Seasonal variability of the Caspian Sea three-dimensional circulation, sea level and air-sea interaction, Ocean Sci., 6, 311-329, doi:10.5194/os6-311-2010, 2010.

Jacob, R., Larson, J., and Ong, E.: M X N Communication and Parallel Interpolation in Community Climate System Model Version, Int. J. High Perform. C., 19, 293-307, 2005.

Kara, B. A., Wallcraft, A. J., Metzger, E. J., and Gunduz, M.: Impacts of freshwater on the seasonal variations of surface salinity and circulation in the Caspian Sea, Cont. Shelf Res., 30, 12111225,2010

Kiehl, J., Hack, J., Bonan, G., Boville, B., Briegleb, B., Williamson, D., and Rasch, P.: Description of the NCAR Community Climate Model (CCM3), Technical Report TN-420+STR, NCAR, 152 pp., 1996.

Kosarev, A. N. and Yablonskaya, E. A.: The Caspian Sea, SPB Academic Publishing, The Hague, 259 pp., 1994.

Kouraev, A. V., Papa, F., Mognard, N. M., Buharizin, P. I., Cazenave, A., Cretaux, J. F., Dozortseva, J., and Remy, F.: Sea ice cover in the Caspian and Aral Seas from historical and satellite data, J. Marine Syst., 47, 89-100, 2004.

Larson, J., Jacob, R., and Ong, E.: The Model Coupling Toolkit: a new Fortran90 toolkit for building multiphysics parallel coupled models, Int. J. High Perform. C., 19, 277-292, 2005.

Legates, D. R. and Willmott, C. J.: Mean Seasonal and Spatial Variability Global Surface Air Temperature, Theor. Appl. Climatol., 41, 11-21, 1990a.

Legates, D. R. and Willmott, C. J.: Mean Seasonal and Spatial Variability in Gauge-Corrected, Global Precipitation, Int. J. Climatol., 10, 111-127, 1990b.

MacCallum, S. N. and Merchant, C. J.: ARC-Lake v1.1, 19952009, University of Edinburgh, School of GeoSciences/European Space Agency, 32 pp., 2011.

Mellor, G. L. and Kantha, L.: An ice-ocean coupled model, J. Geophys. Res., 94, 10937-10954, 1989.

New, M. G., Hulme, M., and Jones, P. D.: Representing twentieth century space time climate fields. Pat II: Development of a 19011996 mean monthly terrestrial climatology, J. Climate, 13, $2217-$ 2238, 2000.

Notaro, M., Holman, K., Zarrin, A., Fluck, E., Vavrus, S., and Bennington, V.: Influence of the Laurentian Great Lakes on Regional Climate, J. Climate, 26, 789-804, doi:10.1175/JCLI-D12-00140.1, 2013.

Oki, T. and Sud, Y. C.: Design of Total Runoff Integrating Pathways (TRIP) - A global river channel network, Earth Interact., 2, 1-37, 1998.

Pal, J. S., Small, E. E., and Eltahir, E. A. B.: Simulation of regionalscale water and energy budgets: representation of subgrid cloud and precipitation processes within RegCM, J. Geophys. Res., 105, 29579-29594, 2000.
Patterson, J. C. and Hamblin, P. F.: Thermal simulation of a lake with winter ice cover, Limnol. Oceanogr., 33, 323-338, 1988.

Ratnam, J. V., Giorgi, F., Kaginalkar, A., and Cozzini, S.: Simulation of the Indian monsoon using the RegCM3-ROMS regional coupled model, Clim. Dynam., 33, 119-139, 2009.

Redler, R., Valcke, S., and Ritzdorf, H.: OASIS4 - a coupling software for next generation earth system modelling, Geosci. Model Dev., 3, 87-104, doi:10.5194/gmd-3-87-2010, 2010.

Reynolds, R. W., Rayner, N. A., Smith, T. M., Stokes, D. C., and Wang, W.: An improved in situ and satellite SST analysis for climate, J. Climate, 15, 1609-1625, 2002.

Rodionov, S.: Global and Regional Climate Interaction: The Caspian Sea Experience, Kluwer Academic, Dordrecht, 1994.

Rossow, W. B. and Schiffer, R. A.: Advances in Understanding Clouds from ISCCP, B. Am. Meteorol. Soc., 80, 2261-2288, 1999.

Schiffer, R. A. and Rossow, W. B.: The International Satellite Cloud Climatology Project (ISCCP): The First Project of the World Climate Research Programme, B. Am. Meteorol. Soc., 64, 779-784, 1983.

Scott, R. W. and Huff, F. A.: Impacts of the Great Lakes on Regional Climate Conditions, J. Great Lakes Res., 22, 845-863, 1996.

Shchepetkin, A. F. and McWilliams, J. C.: The Regional Ocean Modeling following coordinates ocean model, Ocean Model., 9, 347-404, 2005.

Sikiric, M. D., Janekovic, I., and Kuzmic, M.: A new approach to bathymetry smoothing in sigma-coordinate ocean models, Ocean Model., 29, 128-136, 2009.

Small, E. E., Sloan, L. C., Hosteller, S., and Giorgi, F.: Simulating the water balance of the Aral Sea with a coupled regional climate-lake model, J. Geophys. Res., 104, 6583-6602, 1999.

Sur, H. I., Özsoy, E., and Ibrayev, R.: Satellite-derived flow characteristics of the Caspian Sea, in: Satellites, oceanography and society, edited by: Halpern, D., Elsevier Oceanography Series, 63, 289-297, 2000.

Turuncoglu, U. U., Elguindi, N., Giorgi, F., Fournier, N., and Giuliani, G.: Development and validation of a regional coupled atmosphere lake model for the Caspian Sea Basin, Clim. Dynam., doi:10.1007/s00382-012-1623-6, in press, 2012.

Warner, J. C., Sherwood, C. R., Arango, H. G., and Signell, R. P.: Performance of four turbulence closure methods implemented using a generic length scale method, Ocean Model., 8, 81-113, 2005.

Yu, L., Jin, X., and Weller, R. A.: Multidecade Global Flux Datasets from the Objectively Analyzed Air-sea Fluxes (OAFlux) Project: Latent and sensible heat fluxes, ocean evaporation, and related surface meteorological variables. Woods Hole Oceanographic Institution, OAFlux Project Technical Report, OA-200801, 64 pp., Woods Hole, Massachusetts, 2008.

Zeng, X., Zhao, M., and Dickinson, R. E.: Intercomparison of bulk aerodynamic algorithms for computation of sea surface fluxes using TOGA COARE and TAO data, J. Climate, 11, 2628-2644, 1998. 